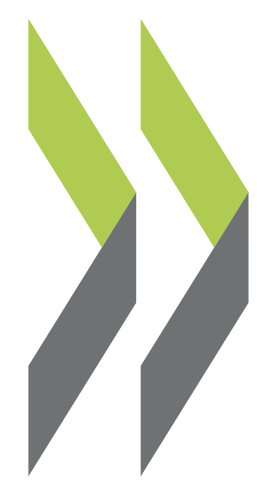

OECD Local Economic and Employment Development (LEED) Papers 2020/07

\title{
An insight into
}

the innovative start-up

landscape of South Tyrol: A OECD language barrier to effective policy transfer? 


\title{
An insight into the innovative start-up landscape of South Tyrol
}

\section{A language barrier to effective policy transfer?}

\begin{abstract}
The characteristics of innovative start-up firms in South Tyrol, the northernmost province of Italy, entirely mountainous, hosting a high-income population belonging to three main language groups. This work is part of a series of thematic papers on sub-national start-up landscapes in Italy, produced by the OECD Trento Centre for Local Development. It represents a first attempt to analyse the effect of the Italian policy framework for young innovative firms at the local level. South Tyrol is home to a relatively small number of registered innovative start-ups, pointing to the presence of obstacles to policy transfer. Evidence suggests that language barriers may play a critical role. Firm dynamism, in particular high-growth and exit trends, the spread of emerging technologies among local start-ups as well as their propensity to uptake national incentives are other major focuses of this work, which concludes with a set of evidence-based recommendations for policy-makers.
\end{abstract}

JEL codes: D22, L26, M13, O38, R12

Keywords: start-up, innovation, entrepreneurship, policy adoption, multi-level governance, local development, firm growth, artificial intelligence

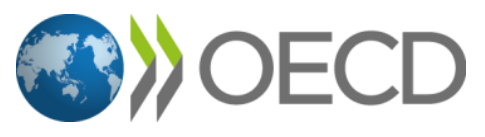




\section{ABOUT THE OECD}

The OECD is a multi-disciplinary inter-governmental organisation of 37 member countries which engages in its work an increasing number of non-members from all regions of the world. The Organisation's core mission today is to help governments work together towards a stronger, cleaner, fairer global economy. Through its network of 250 specialised committees and working groups, the OECD provides a setting where governments compare policy experiences, seek answers to common problems, identify good practice, and co-ordinate domestic and international policies. More information available: www.oecd.org.

\section{ABOUT OECD LOCAL ECONOMIC AND EMPLOYMENT DEVELOPMENT (LEED) PAPERS}

The OECD Local Economic and Employment Development (LEED) Programme Papers present innovative ideas and practical examples on how to boost local development and job creation. A wide range of topics are addressed, such as employment and skills; entrepreneurship; the social economy and social innovation; culture; and local capacity building, among others. The series highlights in particular policies to support disadvantaged places and people, such as the low skilled, the unemployed, migrants, youth and seniors.

This paper is published under the responsibility of the Secretary-General of the OECD. The opinions expressed and the arguments employed herein do not necessarily reflect the official views of OECD member countries.

This paper was authorised for publication by Lamia Kamal-Chaoui, Director, Centre for Entrepreneurship, SMEs, Regions and Cities, OECD.

This document, as well as any statistical data and map included herein, are without prejudice to the status of or sovereignty over any territory, to the delimitation of international frontiers and boundaries and to the name of any territory, city or area.

\section{(C) OECD 2020}

You can copy, download or print OECD content for your own use, and you can include excerpts from OECD publications, databases and multimedia products in your own documents, presentations, blogs, websites and teaching materials, provided that suitable acknowledgement of OECD as source and copyright owner is given. All requests for public or commercial use and translation rights should be submitted to rights@oecd.org. 


\section{Acknowledgements}

This paper was authored by Mattia Corbetta from the OECD Trento Centre for Local Development, part of the Centre for Entrepreneurship, SMEs, Regions and Cities (CFE). It belongs to a series of regional case studies on innovative start-up landscapes in Italy.

The author thanks CFE colleagues Lucia Cusmano (SME and Entrepreneurship Division) and Karen Maguire (Local Employment, Skills and Social Innovation Division) for their helpful suggestions.

Roberto Volpe, international consultant, provided an important contribution to the analysis.

The author is also grateful to the government of the Autonomous Province of Bolzano-Bozen, which gave valuable feedback throughout the preparation of the paper.

The Italian Ministry of Economic Development (MISE) provided an important contribution in terms of data and hands-on comments. Special thanks go to Benedetta Francesconi, Directorate-General for Industrial Policy, Innovation and SMEs.

Finally, the author gratefully acknowledges Elisa Campestrin (Trento Centre for Local Development), who provided editorial assistance. 


\section{Table of contents}

Acknowledgements 3

Executive Summary $\quad 6$

1. Introduction 10

How young and innovative firms contribute to job creation, productivity and inclusiveness $\quad 10$ How policy can support start-up entrepreneurship: two alternative approaches 11 The Italian Start-up Act: a definition of innovative start-ups and support measures 12 Data sources $\quad 14$

Why is the regional level relevant in Italy? $\quad 15$ Notes $\quad 17$

2. The Italian Start-up Act in South Tyrol: how the policy has taken root 18 Start-up registration trends $\quad 18$

Start-up distribution does not reflect population patterns $\quad 21$

South Tyrol's "Missing Entrepreneurs": women and youth participation is still too low 25 Uptake of flagship policy instruments: a penchant for e-government 27 Notes 32

3. Growth trends of innovative start-ups 33

Descriptive statistics: a snapshot as of January 2020

Visualising growth trends over time: a cohort-based analysis 35

Discussion of findings $\quad 40$

$\begin{array}{ll}\text { Notes } & 41\end{array}$

4. Breakdown by economic sector: "traditional" areas and emerging technologies 42

"Traditional" NACE classification of start-ups (and its shortcomings) 42

Identifying start-ups that adopt emerging digital technologies: a topic modelling approach $\quad 43$

Notes 46

5. Main takeaways and policy recommendations $\quad 47$

A language barrier to effective policy transfer? $\quad 47$

High-growth start-ups: is more work needed? $\quad 49$

Start-ups in high-impact sectors: how to find and support them 50

Diversity in start-up entrepreneurship: what can south Tyrol do better? 51

Data availability: closing information gaps and promoting evaluation culture 52

Notes $\quad 55$ 


\section{Tables}

Table 1.1. South Tyrol basic demographic and economic statistics 16

Table 2.1. Distribution of start-ups and population by municipality in South Tyrol 22

Table 2.2. Distribution of registered start-ups across central and inner areas (ACT categories, January 2020) 23

Table 2.3. Relationship between number of innovative start-ups by municipalities and number of German speakers in South Tyrol (OLS regression model)

Table 2.4. Share of access to state-guaranteed bank loans among innovative start-ups in Italian regions and autonomous provinces (January 2020)

Table 2.5. Relationship between rate of innovative start-ups accessing guaranteed loans and GDP per capita, number of registered start-ups, taxable income, provincial level (OLS regression model)

Table 3.1. Turnover of registered innovative start-ups in South Tyrol, summary statistics and comparison with Italy at large (2018 fiscal year, EUR)

Table 3.2. Turnover of innovative start-ups in South Tyrol, key peak values for currently and formerly registered firms, comparison with the rest of Italy (2018 fiscal year, EUR)

Table 3.3. Distribution of employees of registered innovative start-ups in South Tyrol and Italy (January 2020) 35

Table 3.4. Turnover growth of innovative start-ups in South Tyrol and Italy, shares of start-ups by turnover class over time - early adopters (2014-2018)

Table 3.5. Turnover growth of innovative start-ups in South Tyrol and Italy, shares of start-ups by turnover class over time - second wave (2016-2018)

Table 4.1. Distribution of innovative start-ups by economic activity (NACE), South Tyrol and Italy (January 2020)

\section{Figures}

Figure 2.1. Cumulative new innovative start-up registrations in South Tyrol and Trentino (monthly trends, 2013-2019)

Figure 2.2. Cumulative net innovative start-up registrations in South Tyrol and Trentino (2013-2019)

Figure 2.3. Location of the head offices of innovative start-ups in South Tyrol (as of January 2020)

Figure 2.4. Ratio of majority-female registered start-ups by Italian region and autonomous province (January 2020)

Figure 2.5. Ratio of majority-youth (under-35) registered innovative start-ups by Italian region and autonomous province (January 2020)

Figure 2.6. Rate of innovative start-ups that have accessed state-guaranteed bank loans across Italian provinces, and correlation with GDP per capita (January 2020)

Figure 2.7. Ratio of innovative start-ups incorporated online over total registered firms incorporated in the year (2018, 2019)

Figure 3.1. Flows between turnover categories of innovative start-ups in South Tyrol (left) and in Italy (right), early adopters (2014-2018)

Figure 3.2. Flows between turnover categories of innovative start-ups in South Tyrol (left) and in Italy (right), second wave start-ups (2016-2018)

Figure 3.3. Individual growth trajectories of start-ups in South Tyrol, early adopters (2014-2018)

Figure 3.4. Individual growth trajectories of start-ups in South Tyrol, second wave (2016-2018)

Figure 4.1. Top-10 words by beta score in the "emerging digital technologies" topic (LDA topic model, k-value =12), innovative start-ups population (6 April 2020)

Figure 4.2. Share of registered start-ups adopting emerging digital technologies (top-10 gamma percentile) by region and autonomous province (April 2020)

\section{Boxes}

Box 1.1. The evaluation of the Italian Start-up Act (OECD 2018) 13

Box 2.1. Bottlenecks in policy transfer, a long-standing issue of the Italian Start-up Act 20

Box 3.1. Innovative start-ups' employment conundrum $\quad 35$

Box 5.1. Policy recommendations $\quad 54$ 


\section{Executive Summary}

The present document offers an in-depth analysis of the characteristics of innovative start-up firms in the autonomous Province of Bolzano-Bozen (or "South Tyrol"), the northernmost and second largest province of Italy, wholly mountainous, hosting a high-income population belonging to three main language groups. This work is part of a series of thematic papers on regional start-up landscapes in Italy, which represents a first attempt to analyse the effect of Italy's policy framework for young innovative firms at the local level.

Extensive empirical evidence shows that young firms are a key driver to job creation and productivity in all OECD countries. As shown during the coronavirus (COVID-19) pandemic, innovative start-ups can also contribute to societal well-being by offering new solutions to urgent needs, and by facilitating the shift to digital-based work and consumption. Start-up entrepreneurship may also contribute more broadly to social inclusion: however, women and young people are under-represented among founders, revealing deepseated societal and cultural disparities.

Policy-makers have followed two alternative approaches to start-up support: a "selective" approach, targeting only the companies that are assumed to be high-growth, and a "nonselective" approach, creating an enabling environment for all innovative firms, which facilitates entry and exit, and smoothens risk. While identifying high-growth firms fully a priori is challenging, there is an economic argument for supporting start-ups in general in times of crisis, as losses in firm creation and growth have permanent and long-term effects on employment levels.

Italy opted for a mixed approach. In the Italian legislation, "innovative start-ups" are defined as the beneficiaries of a specific scheme launched by the national Government in 2012, the Italian Start-up Act. Its peculiarity is the provision of a legal definition of innovative start-ups, which entitles eligible firms to benefit from an extensive package of support measures, including online incorporation, subsidised loans, and incentives to equity investors. Earlier OECD work reveals how firms benefiting from this scheme have a better economic performance than other eligible entities that do not register, or become registered as an innovative start-up at a later stage. This makes the issue of policy transfer - the mechanisms that allow policies designed by central administrations to catch on at the local level - particularly salient, given that the policy works on self-selection: eligible companies must file an application to qualify as an innovative start-up, and there is evidence that a substantial share of them never do so.

Another distinctive feature of the Italian Start-up Act is its open data policy: by express provision of the law, a vast range of micro-data on beneficiary firms is freely available online, and a structured monitoring system is in place. These datasets represent the main statistical source used for the purposes of the present work.

There are two main reasons of interest for studying the local dimension of Italy's start-up policy. The first is the wide variation observed across regions under most metrics of firm performance: a typical feature of Italy, a country of very large regional disparities that have pervasive effects on entrepreneurial attitudes and outcomes. The second reason lies with Italy's devolved local governance, which confers law-making and spending powers to regional authorities in the field of SME and innovation policy. This decentralised 
setup means that regional authorities have significant discretionary powers to complement national policies and adapt them to local framework conditions.

Some local authorities enjoy particularly extensive delegated powers, and South Tyrol is a case in point. Formally the autonomous Province of Bolzano-Bozen, this jurisdiction is the only part of Italy where a majority of the population does not speak Italian as first language: German is the native tongue of almost $70 \%$ of its residents. South Tyrol is the wealthiest Italian large-area administrative division and shows very high employment rates, as well as reduced income inequality; however, its relatively low educational levels and R\&D expenditure suggest that the reasons for this success does not lie with a "knowledge-based" economy.

As of January 2020, there were 92 registered start-ups in South Tyrol, representing $3.37 \%$ of all young limited companies in this territory. Although the ratio is slightly higher than the national average $(2.98 \%)$, it is noticeably lower than neighbouring Trentino, which has the highest start-up density in the whole country (7.45\%). This means that in Trentino the start-up population is almost twice as large as in South Tyrol, even if the latter is broadly the same size as Trentino in terms of residents (approximately half a million each) and has, in fact, a larger business population overall. The gap in registrations between Trentino and South emerged shortly after policy introduction, and has only widened over time.

All over Italy, innovative start-ups tend to agglomerate in large urban centres, especially those that have the best infrastructure and services. In South Tyrol, this trend is particularly marked, as over $60 \%$ of all registered start-ups are located in the provincial capital, Bolzano-Bozen. While a majority of South Tyroleans live in municipalities with 10000 inhabitants or fewer, the number of start-ups located in small towns is very limited, especially when moving further away from Bolzano-Bozen.

Our analysis suggests that there may be more at play than a mere urban-rural divide, and that linguistic variation may play a part. The main hubs for start-ups in South Tyrol are also the areas with the highest density of Italian-speakers, while mid-size centres with a high share of German speakers have few or no registered start-ups. Indeed, a linear regression analysis at municipality level shows that the number of German-speakers has a negative effect on start-up density even after controlling for total population and the level of peripherality. This finding hints at a language-related policy transfer issue, with members of the German-speaking group apparently less receptive towards this national initiative.

The population of start-up entrepreneurs is also not reflective of overall demographics in other ways. Women are particularly under-represented: just $8.7 \%$ of innovative start-ups in South Tyrol have a majority of females among shareholders, which is by far the lowest ratio in Italy. Innovative start-ups owned by under-35s are also less prevalent in South Tyrol than in Italy at large. This finding is striking, as BolzanoBozen has very high employment rates among these groups; conversely, the regions with the highest representation of women and young entrepreneurs are in the South of the country, which has much higher unemployment and lower labour force participation. This negative correlation between diversity in start-up entrepreneurship and in overall employment strongly suggests that under-represented groups have even fewer incentives to embark on risky entrepreneurial ventures when more opportunities in the "conventional" job market are available.

South Tyrolean start-ups show distinctive patterns in the adoption of policy instruments making up the Italian Start-up Act. Three registered firms in ten (30.1\%) have obtained a loan backed by a public guarantee facility (SME Guarantee Fund), a ratio among the highest in the country. However, this work evidences how access to credit by start-ups is strongly influenced by underlying macro-economic conditions. As South Tyrol has one of the highest GDP per capita in Italy, a linear regression model shows that a $30 \%$ rate of access can be seen as in line or even below expectations, suggesting that there are still gaps in the adoption of this instrument. Conversely, start-ups in South Tyrol have made wide use of two flagship "e-government" instruments: a digital procedure for start-up incorporation, and of the promotional portal startup.registroimprese.it. These instruments are both supervised by the Chamber of Commerce of Bolzano-Bozen, a decentralised, bilingual body. 
As the Italian Start-up Act is aimed at companies in the early stage of their life cycle, an overwhelming majority of innovative start-ups are micro-SMEs: just $0.7 \%$ of all beneficiaries currently registered at the national level recorded a turnover above EUR 2 million in 2018. At a first glance, however, start-ups in South Tyrol are remarkably small even in the Italian context: mean and median turnover values are among the lowest in Italy, and just a handful of firms have a sales volume above EUR 200000 per year. Extending the view to formerly registered start-ups, it emerges that two firms (1.5\%) had a sales volume above EUR 2 million in 2018, which is consistent with national trends.

A look at annual variations in turnover values reveal some dynamism in the South Tyrolean start-up population. Registered firms start extremely small: most have a sales volume of less than EUR 50000 in their first year. Moreover, local start-ups have a higher propensity to close shop than in the rest of Italy: almost one quarter of all firms registered in 2013 and 2014 was no longer operational by 2018. Start-ups that survive normally grow during their registration period, although rarely at a sustained rate: they reach a turnover above EUR 500000 only in very few cases. While in neighbouring Trentino there is a substantial "middle class" of firms with a turnover between EUR 500000 and EUR 1 million, this is almost non-existent in South Tyrol; the share of "millionaire" start-ups is however similar across the two territories.

Finally, an exploratory text analysis of company documentation, based on machine learning techniques (Latent Dirichlet Allocation method for topic modelling), estimated the share of registered start-ups adopting emerging digital technologies, such as artificial intelligence, cloud computing, and big data analytics, across the Italian regions. South Tyrol performs well in this respect: $11.4 \%$ of its start-ups are in the top-10 percentile in Italy in terms of "Al-intensity", meaning that these are more common than in most other parts of the country. This is a partly unexpected finding: according to the conventional NACE categories, South Tyrol has a comparatively low share of start-ups classified as "computer programming". This means that software start-ups in Bolzano-Bozen are more inclined to adopt highly innovative technologies than their peers further south, Rome being a major exception.

The paper concludes with a set of policy recommendations for national and particularly local policy makers. While, at a first sight, the innovative start-up landscape of South Tyrol looks rather "typical" in the Italian context - e.g. because of its average start-up density - there are several place-specific issues that could be tackled. The most prominent is the language divide, which appears a serious drag on the potential of this national policy to support the local entrepreneurial landscape to its full extent, particularly in peri-urban and rural areas. As intermediaries such as legal and fiscal professionals play an important part in policy transfer, a first recommendation is to ensure full and timely availability of information resources about the policy in all official languages. This would facilitate the adoption of the innovative start-up concept by all local business communities, no matter what language community they belong to. However, additional estimates of the unregistered start-up population, e.g. via targeted filtering of the Business Registry or exploitation of text analysis techniques, would allow to measure "missing" innovative start-ups even more precisely.

Secondly, South Tyrol - and Italy at large - need further efforts to promote the emergence of high-growth and high-impact start-ups. On the one hand, Italy needs a "scale-up strategy" alongside the Start-up Act, targeted at firms that have high financial needs and need leeway to carry out large, risky investments: this needs funding as well as large-scale systemic actions, such as a more efficient and trustworthy civil justice. Funding and support services are also crucial: our analysis shows that South Tyrolean start-ups are well positioned to benefit from the increasing attention given by policy-makers to artificial intelligence and digitised manufacturing, and should be put in the condition to exploit effectively the substantial resources devoted by the European Union to develop testing facilities and Digital Innovation Hubs. A specific recommendation regards the need to develop "early warning" systems that help identifying promising startups early in their life cycle: for instance, high growth start-ups tend to have substantial sales volumes since their first or second year of registration already. 
Finally, more focus could be put on championing diversity in the start-up environment, as the rate of female and under-35 founders is extremely low compared to their overall employment rates. As the gaps in innovative entrepreneurship start at a young age, it is sensible to promote the entrepreneurial choice among graduate students and researchers, by providing funding as well as mentoring and advisory services. 


\section{Introduction}

\section{How young and innovative firms contribute to job creation, productivity and inclusiveness}

Enabling start-ups to enter the market and grow is a policy priority across OECD member countries. There is empirical evidence that a thriving landscape of young firms, particularly if technologically innovative, is beneficial for economies and societies.

In all OECD countries, young firms - defined as firms that are five years of age or younger - have a positive impact on job creation. Even if, on average, they account for about $20 \%$ of total employment, they create almost half of all new jobs, meaning that they have a disproportionate effect on aggregate employment. The entry of new firms has in itself a measurable impact on job levels, together with the growth of young incumbents, particularly those that are less than three years old. This is remarkable because just a tiny proportion of start-ups grow significantly after entry: between $2 \%$ and $9 \%$, according to the OECD DynEmp dataset used by the OECD (Criscuolo, Gal and Menon, 2014, p. 32[1]). Even if there is wide cross-country variation, start-ups are subject to "up-or-out" dynamics, meaning that high average rates of growth coexist with low survival rates. Nonetheless, the number of jobs created outweighs those destroyed through bankruptcies and downsizing, while for older firms the net contribution to employment is often slightly negative.

There are also signs that dynamism of young entrants is a driver of aggregate productivity growth (Tushman and Anderson, 1986[2]): through a "creative destruction" process, labour and capital are reallocated away from sluggish inefficient firms to growing highly productivity firms, raising overall aggregate productivity. Where said "up-or-out" dynamics are particularly strong, the exceptional productivity growth of a few high-potential firms more than compensates for the majority of start-ups that stagnate (Haltiwanger, Lane and Spletzer, 1999 ${ }_{[3]}$; Calvino, Criscuolo and Menon, 2016[4]). A case in point are the United States, where the role of new firms explains almost half of all productivity growth in the last three decades (Klenow and $\left.\mathrm{Li}, 2020_{[5]}\right)$.

Above and beyond private market benefits of entrepreneurship, innovative start-ups can play a disproportionately important role in meeting broader social objectives. As also highlighted in recent reports (OECD, 2020a[6]), the COVID-19 pandemic brought to the fore the critical role that start-ups play for the economy. On the one hand, the forced closure of workplaces, schools and places of leisure has catalysed advancements in digital technology as much as dramatically increased its uptake. This opened new market opportunities for digital-based young firms, which may be possibly long-term if the shock results in persistent societal changes. On the other hand, public authorities, such as the European Commission, ${ }^{1}$ have resorted to start-ups to develop innovative solutions meeting urgent problems. These include increasing the availability of medical supplies (Reuters, 2020[7]), developing symptom assessment tools, and support health and well-being during the lockdown (Sifted, 2020[8]).

Young firms may also contribute to social inclusion. For instance, there is evidence that innovative entrepreneurship fosters social mobility in the United States (Aghion et al., 2015, pp. 21-22[9]), while minority communities, particularly those of South-East Asian origin, have played increasingly important 
roles in American science and technology sectors (Stuen, Mobarak and Maskus, 2012, pp. 1143-1176[10]). Indeed, all major start-up hubs, in the US as well as in Europe, are characterised by a high share of entrepreneurs coming from abroad (MISE, 2020a $\left.a_{[11]}\right)$. Nonetheless, patterns in start-up entrepreneurship also reflect societal inequalities, and there are signs that they may even amplify them if no correctives are made. (Aghion et al.[9]), for instance, also identify a significant correlation between innovation performance and higher top income inequality. At the same time, there is extensive empirical evidence that women and youth are strongly under-represented among the self-employed population, and even more so in entrepreneurship with high-growth, income generation (Piacentini, 2013 $\left.{ }_{[12]}\right)$ and sustainability prospects. A joint OECD-EU work on "Missing Entrepreneurs" in the European Union (OECD/European Union, $\left.2019_{[13]}\right)$ showed that this gap is persistent, has become more prominent after the Great Recession, and is only slightly narrowing due to a decrease in self-employment among middle-aged men.

Digital-based business models may hold potential for making entrepreneurship more inclusive. As they entail fewer costs to access the market and reach new customers, they are more suitable for entrepreneurs with less financial resources. However, this potential is still largely untapped, as women and youth are greatly under-represented among digital entrepreneurs as well. In 2018, women accounted for only $15.6 \%$ of digital start-ups in the EU, with no signs of progress over time. Even if programmes to support female and youth start-ups exist - albeit there is a perception that this channel is somewhat underexplored (OECD, 2016, pp. 111-129 $[14])$ - there are factors of disadvantage that are complex to tackle. These include a systematically lower confidence among these groups in their own ability to launch an entrepreneurial venture successfully as well as a more difficult access to strategic resources and funding.

\section{How policy can support start-up entrepreneurship: two alternative approaches}

Policy makers may follow two different approaches in supporting start-up entrepreneurship. The first advocates for concentrating support only on the subset of firms that have "[high] growth potential" (Shane, $2009_{[15]}$ ), which, as seen above, are those that generate most economic benefits. The key assumption of this "selective" approach is that growth can be reliably predicted based on observable characteristics of firms, which can be thereby unambiguously identified. However, econometrics studies have indicated that such explanatory variables at firm and entrepreneur levels are largely overshadowed by randomness (Geroski, 2002[16]; Coad, 2009 [17]; McKelvie and Wiklund, 2010 $\left.{ }_{[18]}\right)$. There is also an objective difficulty in obtaining sufficiently detailed data on "ex ante" characteristics of founders from existing sources - although the growing accumulation of data in the digital age, and development of machine learning techniques, may help making progress in the coming future.

A second, "nonselective" approach eschews prior assumptions of growth potential. Enterprises with desired characteristics, such as technology-intensive business models, should be encouraged by allowing "experimentation", streamlining the regulatory context applying to them, incentivising entry - e.g. by simplified incorporation rules and corporate governance - and making company exit via dissolution or bankruptcy less burdensome. The drive towards experimentation also gives a rationale for smoothening risk on the financial supply side, for instance by providing public guarantees to credit institutions and fiscal incentives to capital investors.

Another argument to endorse large-scale support to young firms is the consequences they suffer in times of economic downturn, such as that brought by the COVID-19 pandemic. New entrants are highly susceptible to liquidity shocks, as they find it more difficult to access traditional funding, and their relationships with suppliers and customers are not yet well established. Even after accounting for massive short-term job losses, the experience of the Great Recession shows that such shocks have a permanent effect of the number of firms created, which in turn results of lower employment levels in the long run (up to $-0.5 \%$ after 14 years). Indeed, to shield the economy from long-term damage, during the pandemic all OECD countries launched a variety of schemes to support SMEs (OECD, 2020 $\left.\mathrm{b}_{[19]}\right)$, and some, such as 
France (Bpifrance, 2020[20]), Germany (BMWi, 2020a[21]), the United Kingdom, (UK Government, 2020[22]) and Italy (MISE, 2020 $\mathrm{b}_{[23]}$ ), have also introduced measures specifically targeted at start-ups.

\section{The Italian Start-up Act: a definition of innovative start-ups and support measures}

Among OECD countries, Italy has followed a distinctive course to support young innovative enterprises. The country's strategy for "innovative start-ups" (start-up innovative) is a mix of the two approaches described in the previous paragraph, as it creates a special playing field for companies with pre-defined characteristics, conferring them a set of facilitations, exemptions, and funding opportunities that are tailored to allow experimentation and smoothen risk.

The "Italian Start-up Act" was introduced in late 2012, as part of the actions undertaken by the Italian government to stimulate economic recovery in the aftermath of the financial crisis. Its main body, articles 25 to 32 of decree-law 179/2012, introduces a broad set of special regulations and incentives aimed at promoting "sustainable growth, technological development, innovative entrepreneurship and youth employment", and thereby contributing to "a new entrepreneurial culture [...], social mobility and the attraction of foreign talents, innovative firms and capital to Italy" (Gazzetta Ufficiale, 2012[24]) (art. 25, par. 1 , the "preamble" of the Act).

This set of regulations is applicable to firms that meet a list of eligibility criteria, which define "innovative start-ups" as a specific type of firms under Italian law. These are limited liability companies established for less than five years, reporting an annual turnover lower than EUR 5 million, and not publicly listed. Their incorporation should not be the result of a branch split or merger from a previous company, and they should not have distributed profits. In addition, eligible firms must have an objects clause ("oggetto sociale") explicitly related to innovation, and should fulfil at least one of the following requirements: R\&D expenditure ratio higher than 15\%; at least one third or two thirds of staff holding a $\mathrm{PhD}$ or a Master's degree respectively; ownership of legal rights for a patent or a software (art. 25, par. 2). Remarkably, the definition does not provide for any sector-related constraint - it is well possible to have registered start-ups in tourism, farming, or retail trade, provided that they meet the innovation-related requirements mentioned above.

The Italian Ministry of Economic Development ("MISE"), the chef-de-file in national policy-making on the matter, advertises the support measures in the package as "benefiting all stages of start-ups' lifecycle, from birth to maturity" (MISE, 2019a[25]). They include, among other things, a digital and free procedure for incorporation, several exemptions from duties, fees and corporate governance requirements, tax breaks for seed- and early-stage investments, a public guarantee facility for access to credit, and simplified bankruptcy regulations (Annex A provides an overview of the Italian Start-up Act's main support measures).

The requirements imply that a firm can hold innovative start-up status until it is five years old, or its turnover exceeds EUR 5 million. For companies that no longer meet one of these conditions, but that still retain a character of technological innovation, the government introduced in 2015 (decree-law 3/2015) a "Tier-2" support scheme for so-called "innovative SMEs" (PMI innovative). This regime offers many of the support measures applicable to start-ups, within limits mostly set by European Union rules on state aid. Its dimensional constraints are coterminous with the European definition of SME, and there are no age limits. The definition is thus intended to capture high-growth innovative "scale-ups", together with older smalland mid-caps that introduced high-tech aspects in their business model (MISE, 2019b[26]).

A distinctive feature of the Italian regulatory framework is self-selection. Eligible firms do not benefit from the policies automatically: legal benefits apply only after they register in a "special directory" (sezione speciale) of the Italian Business Registry. The registry is managed by the Italian Chambers of Commerce (Camere di Commercio), public law bodies that act as an interface between firms and the state for most 
administrative matters. It is worth noting that Chambers of Commerce are decentralised players, traditionally organised at the level of each provincia (Italy's second-level local authority) ${ }^{2}$ and that they also have consulting and promotional duties, as well as merely bureaucratic functions. This, together with their responsibilities in keeping the registry tidy - i.e. by checking whether registered start-ups comply with legal requirements - makes Chambers of Commerce key players in implementation and dissemination of the Italian Start-up Act.

Registration as start-up is voluntary: this obviously implies that nascent and existing companies must be well informed about the policy in order to benefit from it. Linkages with other players of the innovation ecosystem (e.g. start-up incubators and accelerators, investment funds and technology transfer institutions) may increase the likelihood to receive such information. Prior analysis, summarised later in this work, estimated that many eligible firms - potentially, as many as those currently registered - are not aware of the policy framework: this was typically a major issue for "mature" SMEs incorporated before the Italian Start-up Act entered into force, and in general for those enterprises that have fewer formal connections with players in the Italian start-up ecosystem. As a consequence, the number of registered innovative start-ups may not capture the full extent of the potentially eligible population.

The Italian scheme is salient for international policy research for a number of reasons. Arguably, the most remarkable is its attempt to introduce a legal definition of innovative start-up based on objective firm characteristics. This solution is uncommon in other OECD countries, but can be generalised nonetheless, as it is based on publicly available company information. Business characteristics used to define eligible firms, such as age, company form, and financial data, are widely available through public as well as commercial datasets: this potentially allows to identify a firm population comparable to Italian innovative start-ups in any other country where the same information is available. Moreover, there is evidence that the policy enjoys high name recognition in Italy (Menon et al., 2018, pp. 72-74[27]), which supports the thesis that registered firms are an acceptable approximation of the local landscape of innovative entrepreneurship.

As outlined in the next section, the policy monitoring system generates a wealth of statistical evidence of many dimensions of firm development and performance. As a result, a growing corpus of policy analysis literature has emerged (Biancalani, Czarnitzki and Riccaboni, 2020[28]; Del Bosco et al., 2019 [29]; Giraudo, Giudici and Grilli, 2019 [30]; Finaldi, 2018[31]; Demartini, 2018[32]; Scattoni et al., 2019 ${ }_{[33]}$ ). This includes an evaluation exercise performed by the OECD (Menon et al., 2018[27]), which evidenced a significant causal effect of exposure to the policy framework on several economic outcomes. Its main findings are summarised in Box 1.1.

\section{Box 1.1. The evaluation of the Italian Start-up Act (OECD 2018)}

In September 2018, the OECD published a comprehensive evaluation of the Italian "Start-up Act", intended as a set of 19 complementary, "eclectic" policy instruments tied to a legal definition of "innovative start-up" firms.

The key section of the study, a counterfactual analysis based on detailed balance sheet, patent, and bank credit data at firm level, estimate the causal effect of the policy on its beneficiaries. Although preliminary, its findings are that beneficiary firms increase revenues, value added and assets by about $10-15 \%$ percent relative to similar start-ups that did not benefit from it. Enrolled firms are also more likely to receive loans at a lower interest rate, and have a higher probability to receive venture capital funding, although the latter nexus is not necessarily causal.

This evidence is regarded as positive, also in the light of the relatively modest cost of the initiative (estimated at approximately EUR 30 million for the 2013-2016 period). The policy seems to have had 
also other "side" effects, such as an increase in interest for the concept of "start-up" in Italy from 2012 onwards (Menon et al., 2018, pp. 73-75[27]).

However, since the policy has been introduced, Italy has not seen an increase in the amount of venture capital investments, especially in comparison with other major EU economies. Although the Italian Startup Act includes few incentives specifically targeted to this form of finance - and almost exclusively for small-size investments - this may cast doubt over the long-term potential and attractiveness of the Italian start-up ecosystem.

The authors warn that the effects of the Italian Start-up Act depend on the health of the entrepreneurial environment as a whole, as bottlenecks that are detrimental for all businesses can be particularly harmful for start-ups. Contract enforcement, bankruptcy and insolvency laws, education and skills, and digital infrastructure are all mentioned as areas in which Italy needs improvement in order to promote start-up competitiveness. Specific policy recommendations feature calls to amend the current objects clause requirement, and introducing provisions targeted to very high-growth firms, researchers, and to tackle the gender gap (Menon et al., 2018, pp. 87-88[27]).

\section{Data sources}

The provision by law of a specific legal definition of innovative start-up - and, relatedly, the creation of dedicated directories within the national Business Registry - is one of the most distinctive features of the Italian Start-up Act. By express provision of the law, micro-data on innovative start-ups are accessible to anyone online, free of charge, and there are no restrictions to their processing and re-publication. InfoCamere, the IT firm of the Italian Chambers of Commerce running the Business Registry backend, updates datasets once a week, allowing continuous public monitoring. ${ }^{3}$

The Business Registry data available for each of the registered innovative start-ups include, among others, the following items: company name, legal type, geographical location (municipality, province and region), date of incorporation and access to policy, NACE code, size class in terms of turnover, employees and share capital, share of women, young and foreigners among shareholders, and company website.

This paper will use a "historicised" version of this database, which includes all start-ups currently and formerly registered as of the first week of 2020. It also integrates it with parallel monitoring systems on policy measures, such as access to guaranteed loans via the public Guarantee Fund for SMEs, and customary demographic and business performance sources. ${ }^{4}$ Our work is also indebted to the periodic monitoring reports published by MISE on a quarterly basis, which cover business demographics as well as performance of individual policy measures. ${ }^{5}$ Indeed, the final clauses of the Start-up Act commit the Ministry to running a monitoring and evaluation system, which culminates in a yearly report to Parliament signed by the Minister. ${ }^{6}$

Italian innovative start-ups are also interesting for researchers because of large availability of highdefinition text data on their economic activity. As of 2019, innovative start-ups are required by law to fill out and update a public "company profile" on a dedicated platform (startup.registroimprese.it), as a precondition to retain their innovative start-up status every year. By doing so, the legislator aims to put corporate data to a better use, increasing company visibility vis-à-vis customers, business partners and investors, both nationally and internationally - profiles may be filled in both Italian and English.

Profiles are largely composed of blocks of free text, although partly guided. Entrepreneurs are encouraged to provide a short description of their business activity, and explain what makes it technologically innovative. They may include a list of team members and an indication of their age and qualifications (in compliance with the EU GDPR), specify the stage of development reached, and their market of interest. 
The profile also provides for a "self-tagging" system aimed at identification of specific sectorial subgroups that may not emerge from traditional economic activity classifications, such as NACE (see Chapter 4).

\section{Why is the regional level relevant in Italy?}

Even though MISE's official reports regularly offer basic regional and other sub-national breakdown of trends in start-up demographics, firm performance and uptake of support measures, this working paper series represents a first attempt to provide an in-depth analysis of the effect of Italy's policy framework for innovative start-ups in a set of selected Italian regions.

There are two main reasons why studying the local dimension of the Italian Start-up Act is interesting for researchers. The first is purely observational: all data available show wide variation across regions under most metrics. Trends in registrations and exits, spatial distribution, propensity to use specific legal benefits, share of traditionally underrepresented groups, and ultimately firm performance, are all highly uneven. Indeed, Italy is historically a case of a country where framework conditions for entrepreneurship vary greatly, being divided between a richer north, which has better employment statistics, higher business density, and a more efficient public administration, and a poorer south, where the role of public employment (and funding) is relatively more important (OECD, 2018[34]). These framework conditions have a direct impact on the entrepreneurial attitude of the local population and of the performance of new and small businesses at the local level (OECD, 2016, p. 93[14] ), and similar trends can be observed also in the context of the Italian Start-up Act - although, as it will be shown in this working paper series, not always in obvious ways.

The second reason lies in Italy's devolved local governance, which confers significant policy-making powers - including the enactment of legislation in the field of economic development and SMEs, and some tax raising powers - to first-level sub-national units. Moreover, five regions (Valle d'Aosta, Friuli-Venezia Giulia, Trentino-Alto Adige/Südtirol, Sardinia and Sicily) are designated by the Italian Constitution as "autonomous", meaning that they have even more extensive delegated powers. These vary from case to case, disciplined by ad hoc autonomy statutes: for instance, Trentino-Alto Adige/Südtirol further delegates its powers to its constituent province, Trento (also known as "Trentino") and Bolzano-Bozen (in English often "South Tyrol") ${ }^{7}$, which are thus named province autonome ("autonomous provinces").

This devolved setup means that, when transferring and applying national legislation, regional authorities have significant discretionary powers to design additive policy instruments, in order to broaden the impact of these measures, or even supplement them to fill gaps and fix perceived flaws. ${ }^{8}$ During the COVID-19 pandemic, for instance, regional authorities have complemented support action of the national government towards SMEs in several ways, such as smoothening access to finance, streamlining bureaucratic procedures, support to temporarily unemployed workers and teleworkers, and subsidised finance schemes (OECD, 2020c $[35]$ ).

Besides law-making and spending powers, devolved authorities play a part in enhancing accessibility and dissemination of information, by involving public (e.g. development agencies), private-public (e.g. Chambers of Commerce), and private intermediaries (e.g. local accountants) in policy transfer. It is therefore essential for policy makers to have an accurate and nuanced picture of the landscape of beneficiaries of national initiatives in their territories, so that regional measures in the field can be designed in a synergic way, avoiding overlaps and duplications. 
Table 1.1. South Tyrol basic demographic and economic statistics

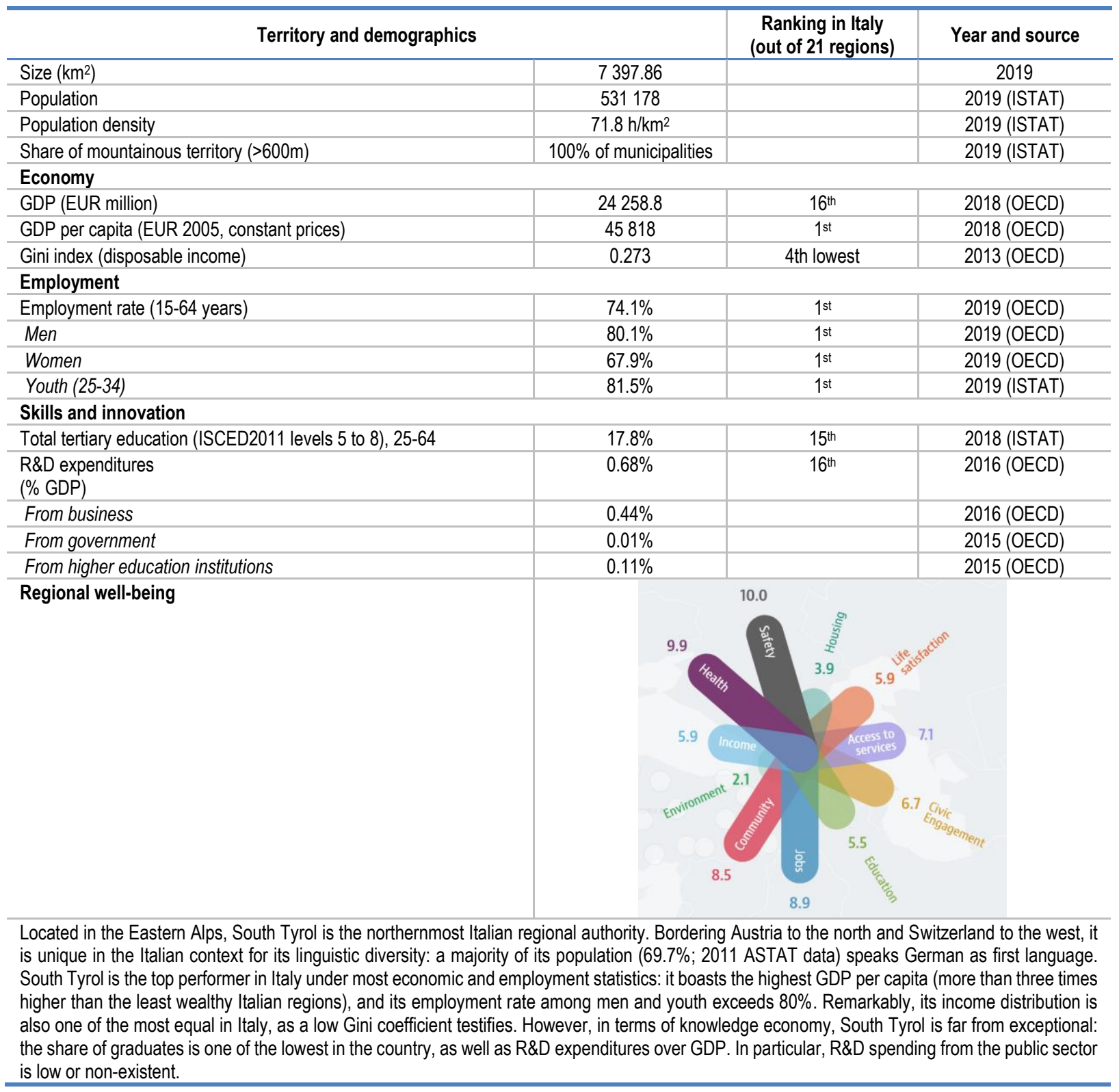

Source: OECD Trento Centre elaboration on OECD and ISTAT data. 


\section{Notes}

${ }^{1}$ See the European Research area "corona platform", which aggregates information about special calls, also launched by national government, to tackle the COVID 19 crisis. URL: https://ec.europa.eu/info/funding-tenders/opportunities/portal/screen/covid-19 [accessed 25 June 2020]

${ }^{2}$ Following efficiency and cost-saving measures, many Chambers of Commerce (primarily in small-sized provinces) have merged in the 2010s. As of 2020, there are 82 Camere, down from the original 105 (roughly one for each provincia and città metropolitana).

${ }^{3}$ The most recent version of the weekly dataset on registered innovative start-ups can be downloaded at the following URL: http://startup.registroimprese.it/isin/report?2\&fileld=startup.zip (.csv format).

${ }^{4}$ Eurostat, ISTAT (Italian National Institute for Statistics), Italian Ministry of Economy and Finance.

5 Repository of MISE periodic reports: "Relazione annuale e rapporti periodici", mise.gov.it: https://www.mise.gov.it/index.php/it/impresa/competitivita-e-nuove-imprese/start-up-innovative/relazioneannuale-e-rapporti-periodici

${ }^{6}$ Editions of the Annual report have been published for 2014, 2015, 2016 and 2017.

${ }^{7}$ This territory, which is statutorily trilingual (German and Ladin are spoken alongside Italian), is officially known in Italian as "Alto Adige".

${ }^{8}$ For instance, the Italian Start-up Act provides for little direct funding options - and no outright grants nor there are major sector-specific initiatives arranged at the national level. 


\section{The Italian Start-up Act in South Tyrol: how the policy has taken root}

\section{Start-up registration trends}

The amount of beneficiary firms represents a first, essential aspect worth of attention when examining the impact brought by the Italian Start-up Act at the local level. Indeed, this number widely varies across the country in ways that, as we will see in the following, are not fully explained by population density or measures of economic activity. As policy access is voluntary and based on self-selection, information asymmetries constitute a major obstacle. Some territories seem to suffer more than others, and in South Tyrol this is particularly visible.

As of 6 January 2020, South Tyrol hosted 92 innovative start-ups, ranking $31^{\text {st }}$ out of 106 Italian provinces, ${ }^{1}$ and $19^{\text {th }}$ out of 21 regions and province autonome. As shown by quarterly reports issued by MISE (MISE, $2020 \mathrm{c}_{[36]}$ ), the ratio between registered firms and total new firms with comparable characteristics (limited companies less than five years old and with annual turnover below EUR 5 million) reported by South Tyrol $(3.37 \%)$ is just slightly above the national average $(2.98 \%)$.

A comparison with South Tyrol's immediate southern neighbour, Trentino, is crucial to put these figures into context. Considering Trentino-Alto Adige/Südtirol ${ }^{2}$ as a whole, it still boasts the highest density across Italian regions (5.25\%). However, the contribution of Trentino is much more prominent. Also as of 6 January 2020, the autonomous Province of Trento hosted 174 innovative start-ups. This means that Trentino's start-up population is almost twice as large as in South Tyrol, even if the two provinces are broadly the same size in terms of residents (approx. half a million each) and the latter has, in fact, a larger business population overall. While over half (54\%) of all young limited companies in the Trentino-Alto Adige/Südtirol region are located in Bolzano-Bozen, the province hosts just one third (34.6\%) of all registered innovative start-ups.

Trentino is admittedly an exceptional case: its innovative start-up density ratio, $7.45 \%$, is by far the highest in Italy. Data therefore suggests that Trentino is a benchmark of effective policy transfer: with this phrase we indicate the mechanisms that allow policies designed by central administrations to catch on at the local level. Given the many similarities between these two territories - governance, economy, demographics it is useful to shed light on how trends in start-up population have diverged.

Looking at "gross" start-up registrations, i.e. the cumulative number of start-ups that have registered month by month, it is immediately clear that the first difference between Trento and Bolzano-Bozen is in timing. Policy transfer in Trentino has been much faster, with a spike in registrations already in spring 2013, just months after the launch of the initiative. For South Tyrol, a similar acceleration can only be seen from 2015 onwards. There is, however, also a difference in pace. While Bolzano-Bozen adds on average 1.9 new beneficiaries per month, Trentino's numbers have kept growing more rapidly, with 3.9 new innovative startups per month on average (Figure 2.1). 
Figure 2.1. Cumulative new innovative start-up registrations in South Tyrol and Trentino (monthly trends, 2013-2019)

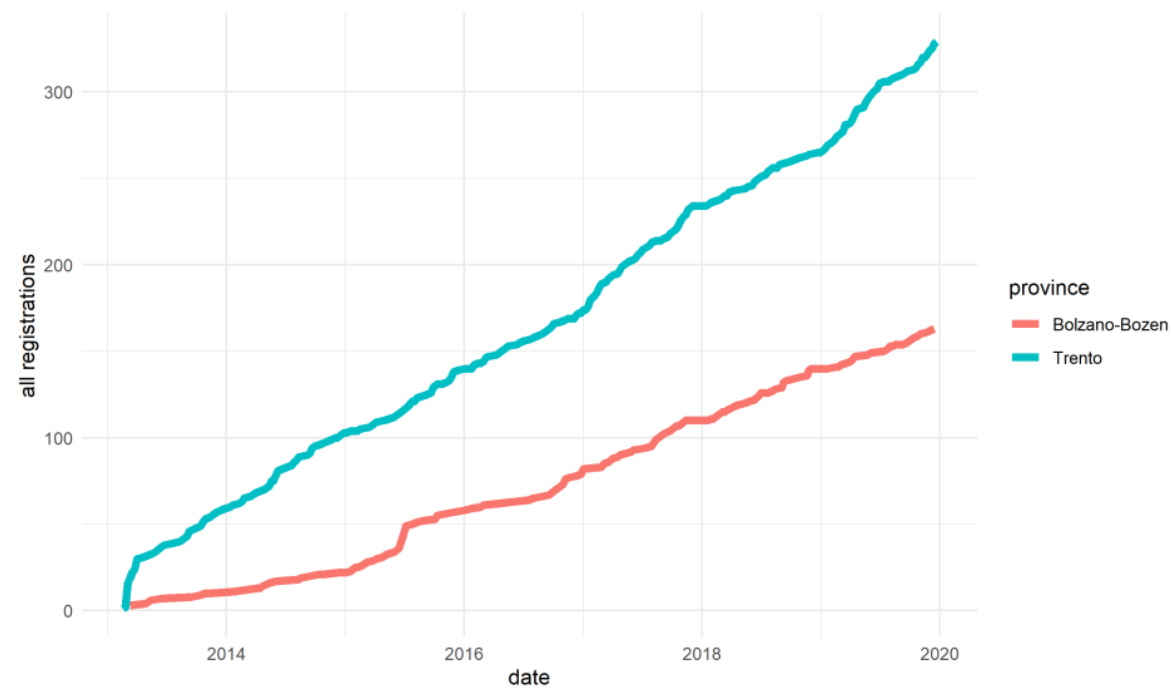

Source: OECD Trento Centre elaboration on Italian Business Registry data.

As stressed in Chapter 1, innovative start-up status is subject to temporal, dimensional, and innovationspecific constraints. While 163 firms in South Tyrol were registered as innovative start-ups for some time between 2013 and 2020, 71 are no longer listed as beneficiaries at the reference date, due to dissolution or loss of eligibility requirements. The latter case applies to all firms that obtained their "special status" in 2013 and 2014, as the ones that are still in operations are more than five years old by now.

It is therefore useful to look at net registration trends, i.e. the number of firms that entered the registry minus those that left it in the same month. If the pace of new registrations is stable - or grows slowly over time, we should expect the total number of registered start-ups to "stabilise", with the number of firms leaving the registry roughly equalling new entrants over the long term.

Trends for South Tyrol are indeed consistent with this pattern. As shown in Figure 2.2, the number of registered start-ups in every week has been overall constant since mid-2018: Bolzano-Bozen has never had more than 92 start-ups registered in any given month, a peak that was hit for the first time in July 2018 already. Whereas this is a "normal" trend in the Italian context, regions with a sustained number of new registrations follow a different curve: this is the case of Trento, for which, albeit with occasional falls due to the older "cohorts" leaving the policy, numbers have kept growing in the past two years. 
Figure 2.2. Cumulative net innovative start-up registrations in South Tyrol and Trentino (2013-2019)

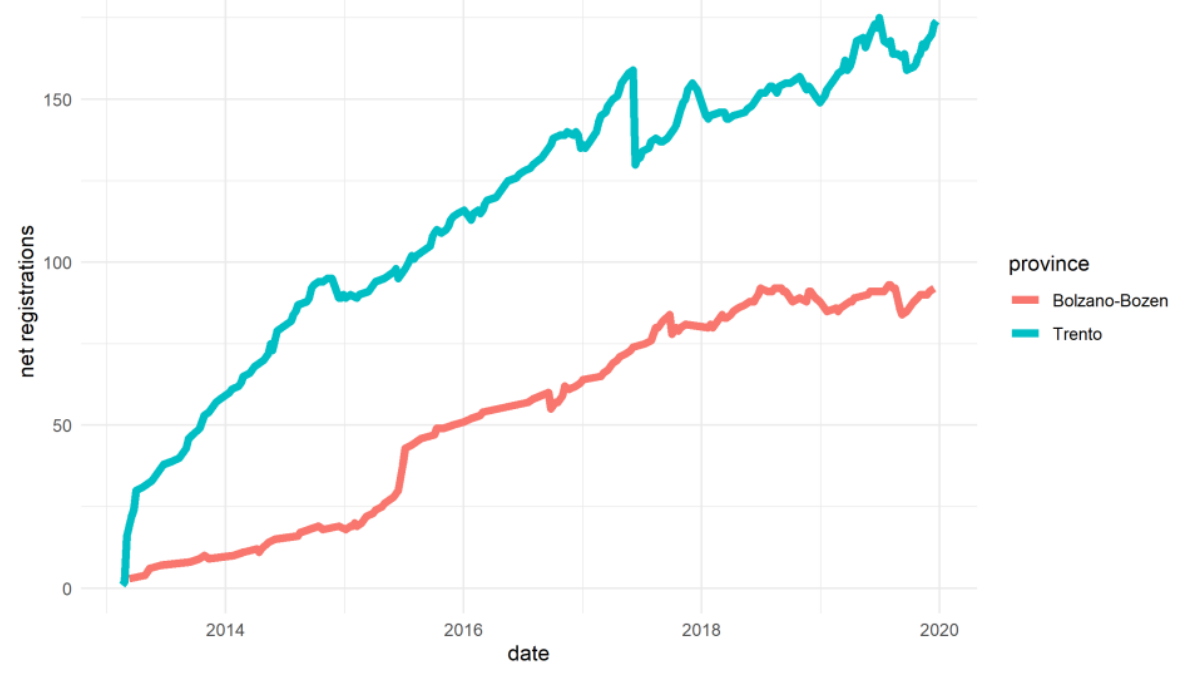

Source: OECD Trento Centre elaboration on Italian Business Registry data.

There has been then an important difference in effectiveness of policy transfer between Trentino and South Tyrol: some reasons for this will be discussed in the rest of this work. It must however be said that the issue is far from being limited to South Tyrol. Previous studies shown that the population of eligible firms all over Italy that did not register may be as large as the "official" population (Box 2.1).

\section{Box 2.1. Bottlenecks in policy transfer, a long-standing issue of the Italian Start-up Act}

The 2016 edition of MISE's Annual Report to Parliament on the Italian Start-up Act (MISE, 2016 $[37]$ ) offered evidence that many young firms across the country were not benefiting from the national policy for innovative start-ups because they were unaware of it.

InfoCamere, the IT firm in charge of the Italian Business Registry, had carried out an analysis aimed at measuring the amount of "missing" innovative start-ups, i.e. firms that, in spite of being formally eligible, had not entered into policy up to then. The query targeted the general "non-start-up" section of the Business Registry (containing all Italian limited companies but innovative start-ups, innovative SMEs, as well as other minor firm groups), by applying a filter based on some of the main requirements set forth by the law (e.g. being a limited company, ownership of a patent etc.).

On 7 March 2016, the analysis found in the "non-start-up" section of the Business Registry 4969 "missing" innovative start-ups, almost equal to the number of firms registered at the time (5 145 firms as of 31 December 2015).

It should be noted that the estimate was conservative, as the filter applied to track the innovative character of firms (i.e. the ownership of a patent or software) derives from the most stringent requirement among the three alternatives set forth by the law. In fact, the Business Registry does not allow a structural query based on R\&D or qualified workforce ratios - whose selection by firms during self-assessment (see par 1.2) for a concise description of the procedure for entry into policy) is far more common than the ownership of intellectual property rights. 
Local policy makers should consider the matter carefully, as this is far from a mere administrative or public communication issue. The presence of innovative start-ups is increasingly seen as a key indicator of the propensity for innovation of regional entrepreneurial ecosystems - in turn one of the core determinants of productivity. For instance, the number of innovative start-ups is part of the basket of indicators used by II Sole 24 Ore, Italy's main financial newspaper, to draw up the business climate section of its renowned annual ranking on the quality of life in Italian cities (II Sole 24 Ore, 2020[38]).

\section{Start-up distribution does not reflect population patterns}

All over Italy, innovative start-ups tend to be located in large urban centres, and even more so in the major economic and population hubs. South Tyrol is no exception: as of January $2020,63 \%$ of all registered start-ups (58 out of 92 ) were incorporated in the provincial capital, Bolzano-Bozen. This concentration ratio is indeed higher than the national average: in other Italian regions, the share of firms incorporated in the regional capital is $44 \%$. The only other area in the region that shows some agglomeration is Merano-Meran, the second most populated municipality in the province. Even if other 21 municipalities are represented, none hosts more than three start-ups each (Figure 2.3).

Figure 2.3. Location of the head offices of innovative start-ups in South Tyrol (as of January 2020)

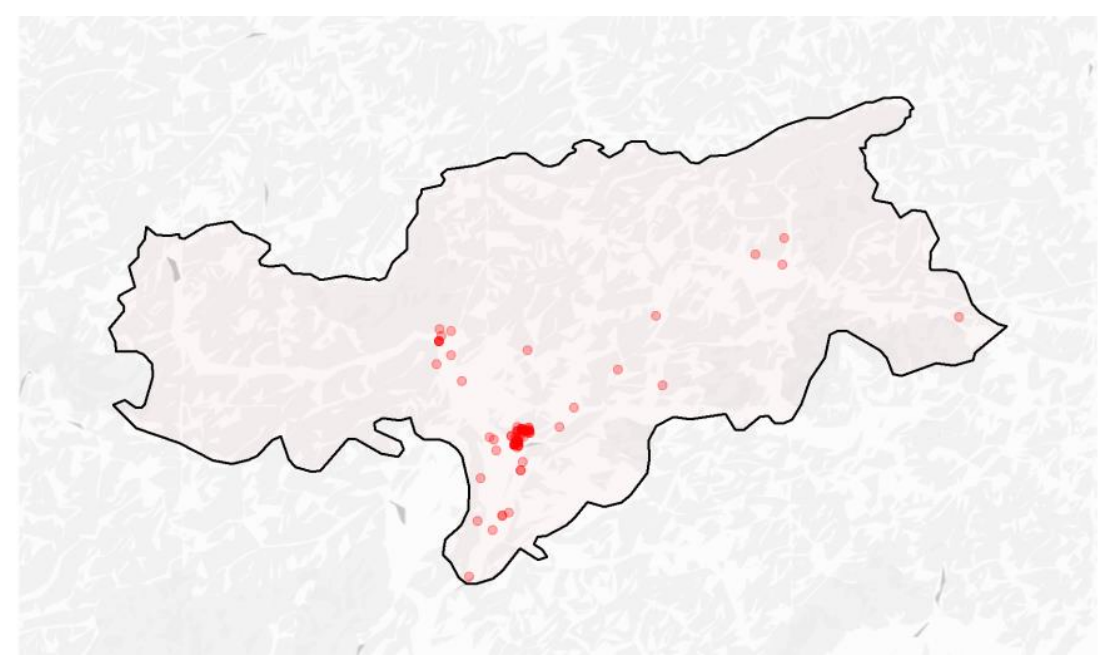

Note: darker hues indicate that multiple start-ups have their office at that location, and thus that there is higher density in that area. Start-ups are clearly heavily concentrated in Bolzano-Bozen and in close municipalities in the Southern part of the province. The second minor cluster, to the north-east, is Merano-Meran.

Source: OECD Trento Centre elaboration on Italian Business Registry data. The map is created in $\mathrm{R}$ with the ggmap package.

The start-up map of South Tyrol appears fairly empty besides the main clusters in Bolzano-Bozen and a "flurry" of points mostly in its south. This is only very partly reflective of the human geography of South Tyrol, which is actually much more spread out. A majority of South Tyroleans live in municipalities with 10000 inhabitants or fewer, and most of them live in towns with 5000 people or less. Bolzano-Bozen, which is the only comune with over 100000 inhabitants, is home to just $20 \%$ of South Tyrol's population (Table 2.1). 
Table 2.1. Distribution of start-ups and population by municipality in South Tyrol

\begin{tabular}{l|r|r|r|r|r|r}
\hline \multicolumn{1}{|c|}{ Municipality or class } & Start-ups & $\begin{array}{c}\text { \% South Tyrol } \\
\text { start-ups }\end{array}$ & $\begin{array}{l}\text { Municipalities } \\
\text { with start-ups }\end{array}$ & $\begin{array}{c}\text { Municipality } \\
\text { in class }\end{array}$ & $\begin{array}{c}\text { Population } \\
\text { (2019) }\end{array}$ & $\begin{array}{c}\text { \% South Tyrol } \\
\text { population }\end{array}$ \\
\hline Bolzano-Bozen & 58 & 63.0 & - & - & 107885 & 20.2 \\
\hline Merano-Meran & 8 & 8.7 & - & - & 41203 & 7.7 \\
\hline $10000-50000$ residents & 9 & 9.8 & $5^{*}$ & 5 & 85084 & 16.0 \\
\hline $5000-10000$ residents & 5 & 5.4 & $4^{* *}$ & 14 & 87198 & 16.3 \\
\hline $1000-5000$ residents & 12 & 13.0 & $10^{* * *}$ & 80 & 202685 & 38.0 \\
\hline Fewer than 1 000 residents & 0 & 0.0 & 0 & 15 & 9384 & 1.8 \\
\hline Totals & 92 & 100.0 & 21 & 116 & 533439 & 100.0 \\
\hline
\end{tabular}

Note: * Appiano s.s.d.v/Eppan a.d.W (3 innovative start-ups), Laives/Leifers (3), Bressanone/Brixen (1), Brunico/Bruneck (1), Lana (1). ** Renon/Ritten (2), Caldaro s.s.d.v/Kaltern a.d.W., Egna/Neumarkt, Sarentino/Sarntal (all 1). *** Ora/Auer (3), Falzes/Pfalzen, Gais, Gargazzone/Gargazon, Laion/Lajen, Ortisei/St. Ulrich/Urtijëi, Postal/Burgstall, Salorno s.s.d.v/Salurn a.d.W, Sesto/Sexten, Termeno s.s.d.v./Tramin a.d.W. (all 1).

Source: OECD Trento Centre elaboration on Italian Business Registry and ISTAT data.

\section{A urban-rural divide...}

There is a clear imbalance between the distribution of the population in South Tyrol - which is heavily located in small and micro-municipalities - and of registered start-ups - which are predominantly located in urban areas. However, the magnitude of local units is not always a proxy of their distance from main population centres, as small municipalities could be close or well connected to major urban areas, or being attractive for innovative start-ups for other reasons (e.g. lower rental costs).

To shed light on this aspect, it is useful to adopt a more refined measure of "remoteness", such as that introduced in 2014 by Italy's "National Strategy for Inner Areas" (aree interne). Responsibility for implementation lies with a central Agency for Territorial Cohesion (Agenzia per la Coesione Territoriale, "ACT"). In this classification, "inner areas" do not necessarily correspond to "rural areas", but are identified based on the physical distance to a Service Provision Centre. A municipality (or cluster of municipalities) is identified as such a centre ("hub") if it hosts schools of every educational grade, major hospitals, and well-connected train stations.

According to this definition, the mountainous but highly developed regions of the Italian North-East will tend to be less peripheral than the infrastructure-deprived South. Indeed, while being a highly-mountainous region, South Tyrol is not very "peripheral" under this measure: $60 \%$ of its population lives in so-called central areas, equally divided between hubs (Bolzano-Bozen, Merano-Meran, and Vipiteno-Sterzing) and "outlying areas", which are in an intermediate position between inner areas and main population centres.

The distribution of start-ups in South Tyrol is however even more concentrated towards main hubs. Over $70 \%$ of start-ups are based in "hubs", a ratio that matches the national average. Indeed, its distribution resembles more closely that of regions like Lombardy, Piedmont or Emilia-Romagna (which include major cities that are also among the main start-up hubs in the country: Milan, Turin and Bologna) than that of Trentino. Whereas Trentino has a high density of start-ups in outlying areas, in South Tyrol this category has very little representation, even if over $30 \%$ of its population lives there (Table 2.2). 
Table 2.2. Distribution of registered start-ups across central and inner areas (ACT categories, January 2020)

\begin{tabular}{|c|c|c|c|c|c|c|}
\hline \multirow[b]{2}{*}{ Region } & \multicolumn{3}{|c|}{ Central areas } & \multicolumn{3}{|c|}{ Inner areas } \\
\hline & A. Hubs & $\begin{array}{c}\text { B. Inter- } \\
\text { municipal hub }\end{array}$ & C. Outlying area & $\begin{array}{c}\text { D. Intermediate } \\
\text { area }\end{array}$ & $\begin{array}{l}\text { E. Peripheral } \\
\text { area }\end{array}$ & $\begin{array}{c}\text { F. Ultra- } \\
\text { peripheral area }\end{array}$ \\
\hline Lazio & $91.0 \%$ & & $3.3 \%$ & $5.0 \%$ & $0.7 \%$ & \\
\hline Liguria & $82.7 \%$ & $8.4 \%$ & $7.9 \%$ & $1.0 \%$ & & \\
\hline Lombardy & $79.5 \%$ & $2.9 \%$ & $15.7 \%$ & $1.5 \%$ & $0.3 \%$ & $<0.1 \%$ \\
\hline Piedmont & $78.3 \%$ & $1.8 \%$ & $16.6 \%$ & $2.8 \%$ & $0.5 \%$ & \\
\hline Emilia-Romagna & $71.8 \%$ & $1.2 \%$ & $22.5 \%$ & $3.4 \%$ & $1.1 \%$ & \\
\hline Bolzano/Bozen & $\begin{array}{c}71.7 \% \\
\text { (6 } 6^{\text {th }} \text { in Italy) }\end{array}$ & & $\begin{array}{c}18.5 \% \\
\left(12^{\text {th }} \text { in Italy) }\right.\end{array}$ & $\begin{array}{c}5.4 \% \\
\left(14^{\text {th }} \text { in ltaly) }\right.\end{array}$ & $\begin{array}{c}4.3 \% \\
\text { (8 } 8^{\text {th }} \text { in Italy) }\end{array}$ & \\
\hline Tuscany & $69.0 \%$ & $5.0 \%$ & $21.5 \%$ & $3.8 \%$ & $0.7 \%$ & \\
\hline Friuli-Venezia Giulia & $68.8 \%$ & & $26.4 \%$ & $4.8 \%$ & & \\
\hline Umbria & $63.1 \%$ & $3.7 \%$ & $18.7 \%$ & $13.4 \%$ & $1.1 \%$ & \\
\hline Sardinia & $62.0 \%$ & & $10.9 \%$ & $4.7 \%$ & $11.6 \%$ & $10.9 \%$ \\
\hline Campania & $60.3 \%$ & $5.9 \%$ & $23.5 \%$ & $7.7 \%$ & $2.2 \%$ & \\
\hline Basilicata & $60.0 \%$ & & $3.8 \%$ & $6.7 \%$ & $19.0 \%$ & $10.5 \%$ \\
\hline Sicily & $59.6 \%$ & $3.1 \%$ & $14.6 \%$ & $13.8 \%$ & $7.8 \%$ & $1.0 \%$ \\
\hline Veneto & $59.1 \%$ & $1.0 \%$ & $29.2 \%$ & $9.8 \%$ & $0.9 \%$ & \\
\hline Abruzzo & $57.7 \%$ & $4.7 \%$ & $20.9 \%$ & $13.0 \%$ & $3.3 \%$ & $0.5 \%$ \\
\hline Apulia & $56.4 \%$ & $3.0 \%$ & $22.3 \%$ & $13.7 \%$ & $4.2 \%$ & $0.5 \%$ \\
\hline Marche & $54.4 \%$ & $8.1 \%$ & $25.0 \%$ & $10.8 \%$ & $1.7 \%$ & \\
\hline Calabria & $50.6 \%$ & $0.8 \%$ & $23.4 \%$ & $16.6 \%$ & $7.2 \%$ & $1.5 \%$ \\
\hline Trento & $45.4 \%$ & & $34.5 \%$ & $14.9 \%$ & $4.6 \%$ & $0.6 \%$ \\
\hline Molise & $45.0 \%$ & & $16.3 \%$ & $26.3 \%$ & $12.5 \%$ & \\
\hline Aosta Valley & $27.3 \%$ & & $31.8 \%$ & $36.4 \%$ & $4.5 \%$ & \\
\hline ITALY & $70.8 \%$ & $2.6 \%$ & $18.0 \%$ & $6.2 \%$ & $2.0 \%$ & $0.4 \%$ \\
\hline
\end{tabular}

Source: OECD Trento Centre elaboration on Italian Business Registry and Agenzia per la Coesione Territoriale data.

\section{...Or a language divide?}

As discussed in the introduction, South Tyrol is unique in Italy being the only part of the country where Italian is not the main language. Almost $70 \%$ of its population declares German as mother tongue, with Italian native speakers making up around $25 \%$. The rest speaks Ladin, a distinct language native of valleys in the Italian Dolomites.

Italian native speakers live primarily in the largest municipalities and, in general, in urban areas. BolzanoBozen is majority-Italian, as well as a handful of surrounding municipalities in the Bassa Atesina subregion, near the border with Trentino. Merano-Meran displays almost a 50-50 split, with a very narrow German majority. In the remaining municipalities, where most local residents live, German speakers are the overwhelming majority: in the areas further away from Bolzano-Bozen, such as the most easterly and westerly valleys, there are few or no Italian-speakers at all. Ladin-speakers are mostly found in the east (Val Gardena), where they are dominant in several municipalities.

The language divide in South Tyrol coincides in good measure with the urban-rural divide - or, to be precise, with the large centre-small municipality divide, as few places in South Tyrol are "inner areas" in a true sense. For this reason only, it is to be expected that there are much more start-ups in territories with a higher density of Italians. Nonetheless, the distribution of start-ups appears at a first glance even more slanted towards Italian majority areas than expected. Mid-size towns with a clear German majority have very few start-ups (Bressanone-Brixen and Brunico-Bruneck, one each) or none (Vipiteno-Sterzing). 
This intuition is supported by econometric analysis. By running a multivariate regression with the number of start-ups by municipality as dependent variable, and total population, (estimated) number of native German speakers and level of peripherality (as per ACT classification) as independent variables, it emerges that there is a negative and highly significant coefficient for the number of German-speakers. The unstandardised coefficient is slightly larger than the positive number seen for population, meaning that the "deflationary" effect of the number of German-speakers is stronger than the positive effect that an increase in population would have. Table 2.3 should be read as follows: all other things considered (including total population, which has obviously a positive effect on the number of registered start-ups), while there are on average 0.73 additional start-ups per municipality for each increase by 1000 inhabitants, there are 0.74 fewer registered firms for each increase by 1000 German speakers - or, in other words, one fewer startup every 1344 additional German speakers.

\section{Table 2.3. Relationship between number of innovative start-ups by municipalities and number of German speakers in South Tyrol (OLS regression model)}

\begin{tabular}{|c|c|c|c|c|}
\hline & \multicolumn{4}{|c|}{ Dependent variable } \\
\hline & \multicolumn{4}{|c|}{ No. registered start-ups per municipality, South Tyrol } \\
\hline & Estimate & std.error & statistic & p.value \\
\hline Constant & -2.603 & 0.91090 & -2.85796 & 0.00511 \\
\hline Population 2019 & 0.00073 & 0.00002 & 36.70773 & $0.000^{* * *}$ \\
\hline $\begin{array}{l}\text { German-speaking } \quad \text { population } \\
\text { (estimate, 2019) }\end{array}$ & -0.00074 & 0.00005 & -15.11067 & $0.000^{* * *}$ \\
\hline ACT class: Outlying & 2.384 & 0.88064 & 2.70723 & $0.00788^{* * *}$ \\
\hline ACT class: Intermediate & 2.541 & 0.89670 & 2.83340 & $0.00549^{* * *}$ \\
\hline ACT class: Peripheral & 2.404 & 0.89810 & 2.67683 & $0.00858^{* * *}$ \\
\hline ACT class: Ultra-peripheral & 2.431 & 0.99063 & 2.45465 & $0.01568^{* *}$ \\
\hline Observations & 116 & & & \\
\hline R-squared & 0.965 & & & \\
\hline Adjusted R-squared & 0.963 & & & \\
\hline Residual standard error & 1.048 & & & \\
\hline F-statistic & 497.845 & & & \\
\hline
\end{tabular}

Source: OECD Trento Centre elaboration on Italian Business Registry and Agenzia per la Coesione Territoriale data.

The finding is very significant for local policy-makers. This exploratory analysis suggests that there are differential policy transfer dynamics across language communities, with German-speaking ones having been less receptive towards this policy framework to an extent that cannot be fully explained by other relevant variables, such as peripherality or population magnitude. It is plausible that this national policy has not had the same reach towards German-speaking entrepreneurs as it had in the rest of Italy: different networks, media bubbles, and perhaps lack of high-quality legal sources in German on the matter might all play a part.

As correlation is not causation, measuring the influence of the language divide is not straightforward. If we assumed, however, that Trentino is a suitable term of comparison, the effect would be massive, with South Tyrol hosting much fewer beneficiaries than under an optimal policy transfer strategy. Indeed, several other figures presented in the rest of this report point in the direction of significant adoption gaps, and in general that the Italian Start-up Act is far from deploying its full potential in this territory. 


\section{South Tyrol's "Missing Entrepreneurs": women and youth participation is still too low}

Datasets from the Italian Chambers of Commerce allow us to measure the share of innovative start-ups led prevalently by women, young people, and non-Italian citizens. Women-led innovative start-ups are here defined as all companies in which women's share in the ownership and governance of society is, overall, the majority. ${ }^{3}$ The same rules apply to foreigners and youth, which are defined as individuals that are under 35 years of age.

As shown in OECD's "Missing Entrepreneurs 2019" report (OECD/European Union, 2019[13]), firms led prevalently by women, young and foreigners are under-represented in most member countries of the Organisation - for instance, young women are only $60 \%$ as likely as young men to be self-employed.

Start-up entrepreneurs in South Tyrol are, as expected, predominantly men. However, the share of startups founded and run primarily by women is particularly low. With an $8.7 \%$ ratio, South Tyrol is last in Italy for "women-majority" start-ups. This value is almost five percentage points below the national average (13.4\%); across Italian regions only Friuli-Venezia Giulia also exhibits a share under 10\%. Neighbouring Trento, as well as most other regions in the north of Italy, also shows similarly low values compared to their peers in the South (Figure 2.4).

Innovative start-ups owned by under-35s are less prevalent in South Tyrol than in Italy at large, as $16.3 \%$ of registered firms are predominantly managed by people of this age group: the fifth-lowest ratio in the country, over three percentage points below the national share of $19.7 \%$. In this case as well it is possible to spot a downward correlation between income and shares, with low income Southern regions taking clear leads under this indicator. The relationship is however less straightforward, than that seen for femalemajority start-ups, as in major hubs in the North (Piedmont, Lombardy) the rate of youth-owned start-ups is fairly high (Figure 2.5).

Figure 2.4. Ratio of majority-female registered start-ups by Italian region and autonomous province (January 2020)

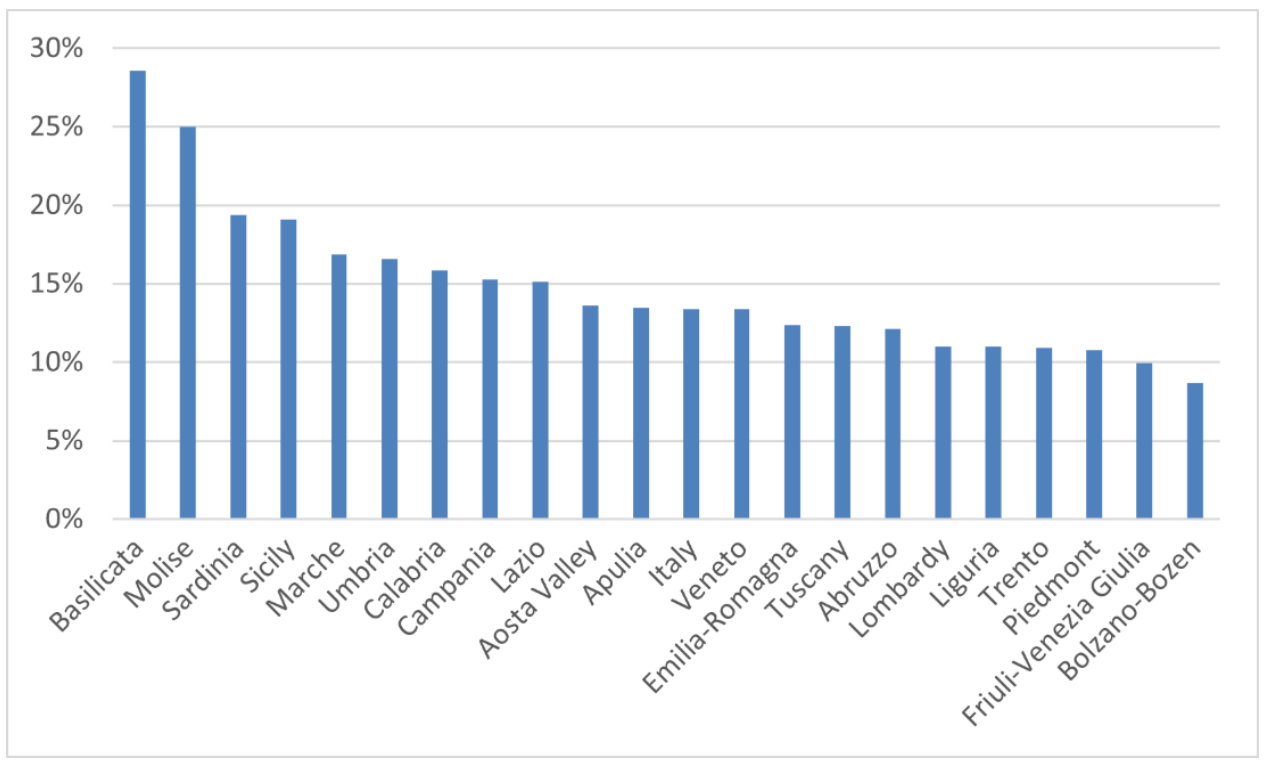

Source: OECD Trento Centre elaboration on Italian Business Registry data. 
Figure 2.5. Ratio of majority-youth (under-35) registered innovative start-ups by Italian region and autonomous province (January 2020)

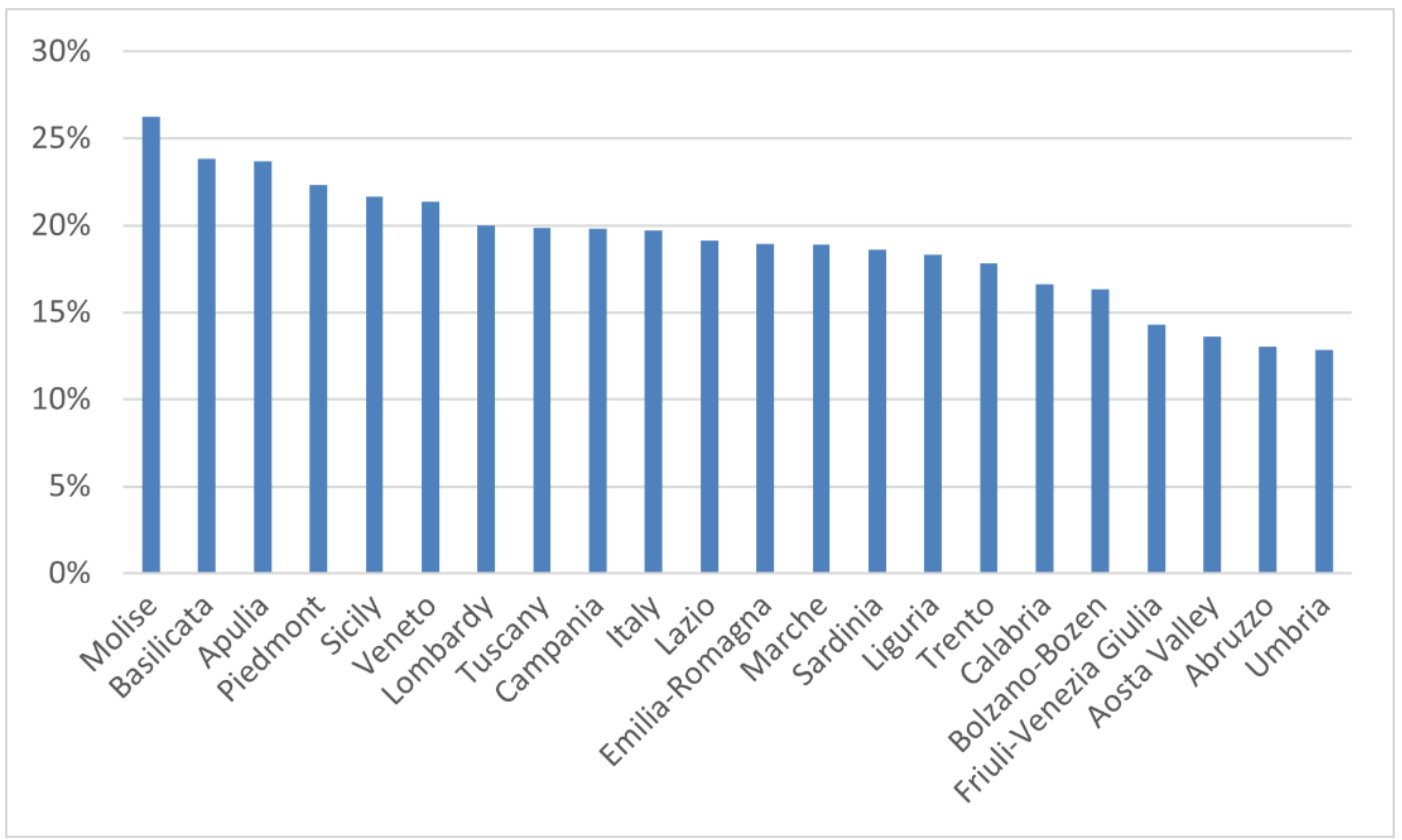

Source: OECD Trento Centre elaboration on Italian Business Registry data.

South Tyrol ranks above the national average in terms of foreign-owned start-ups: its $4.3 \%$ share is the $7^{\text {th }}$ highest in the country. South Tyrol is however outperformed by other border regions such as Aosta Valley and Friuli-Venezia Giulia, which suggests that the multi-lingual local environment and the excellent connections with continental Europe - particularly the German language sphere - through the Brenner corridor are not fully exploited. This aspect could be taken into account by policy makers, as research focusing on the European Union shows that self-employed immigrants born outside the EU or in another EU member state are respectively as likely or just slightly less likely as self-employed born in the reporting EU country to have employees (OECD/European Union, 2019, p. 167[13]).

South Tyrol's low numbers in terms of women and youth representation run opposite to general labour market trends. Statistics show how the autonomous Province of Bolzano-Bozen has, by some distance, the highest labour force participation of women in the country. The same applies to youth, regardless of the "cut-off" chosen (52.5\% for the $15-29$ age group, and a whopping $81.5 \%$ in the $25-34$ cohort: over 20 percentage points above national levels). A similar observation can be made for the other autonomous provinces and regions in the North-East, Trentino or for Friuli-Venezia Giulia, which are both among the best performers in terms of youth and female employment. Conversely, in the Southern regions that have relatively more women and young people among start-up founders, often less than $30 \%$ of women and not even $20 \%$ of under-29s are in work. ${ }^{4}$

These figures strongly suggest that the incidence of female and youth-owned start-ups is influenced by a wider availability in the South of targeted public support schemes offering more favourable conditions to underrepresented groups: ${ }^{5}$ an effect of national and European cohesion policies, as well as of most acute hardship faced by Southern innovative firms in raising funds via market channels, which make public funding even more desirable. It is also possible to assume that in the South there is a component of "necessity-driven entrepreneurship", which is less prominent in the North and in high-income South Tyrol in particular, as disadvantaged groups find it easier to get permanent, well-paid dependent employment, and are therefore less likely to opt for risky entrepreneurial ventures. 


\section{Uptake of flagship policy instruments: a penchant for e-government}

While South Tyrol shows sign of inefficiencies in policy transfer, it performs relatively well in policy uptake, intended as the rate of adoption of the specific instruments offered by the Italian Start-up Act. In other words, information struggles to reach the ground in Bolzano-Bozen, but when it does, it may be used more effectively than elsewhere in Italy.

\section{SME Guarantee Fund}

As evidenced by the OECD evaluation (Menon et al., 2018[27]), access to the Public Guarantee Fund for SMEs ("FGPMI", Fondo di Garanzia per le piccole e medie imprese) is a key determinant for growth in beneficiaries of the Italian start-up policy, and has also a positive impact on value added, labour productivity, and propensity to patent. Compared to other firms, innovative start-ups benefit from lower interest rates and receive more funding (by around 14 percentage points). However, data show that only a minority $(20.5 \%)$ of registered firms obtain a subsidised loan.

The Italian North-East is a partial exception, with uptake rates higher than in the rest of the country (Table 2.4). In South Tyrol, three registered start-ups in ten (30.1\%) obtained a state-guaranteed loan, which is the second highest ratio in the country; only next-door Trentino does better (31.3\%). When comparing Bolzano-Bozen with other provinces, it ranks somewhat lower $\left(16^{\text {th }}\right)$, but it is mostly outperformed by unrepresentative areas with very small start-up populations.

Table 2.4. Share of access to state-guaranteed bank loans among innovative start-ups in Italian regions and autonomous provinces (January 2020)

\begin{tabular}{l|c|c|c}
\hline Region & No. beneficiaries & No. registered & Ratio \\
\hline Trento & 103 & 329 & $31.3 \%$ \\
\hline Bolzano/Bozen & 49 & 163 & $30.1 \%$ \\
\hline Aosta Valley & 10 & 35 & $28.6 \%$ \\
\hline Friuli-Venezia Giulia & 108 & 385 & $28.1 \%$ \\
\hline Liguria & 81 & 289 & $28.0 \%$ \\
\hline Emilia-Romagna & 487 & 1740 & $28.0 \%$ \\
\hline Umbria & 81 & 293 & $27.6 \%$ \\
\hline Veneto & 352 & 1446 & $24.3 \%$ \\
\hline Lombardy & 965 & 4063 & $23.8 \%$ \\
\hline Piedmont & 231 & 991 & $23.3 \%$ \\
\hline ITALY & 3394 & 16551 & $20.5 \%$ \\
\hline Abruzzo & 70 & 344 & $20.3 \%$ \\
\hline Marche & 130 & 639 & $20.3 \%$ \\
\hline Campania & 173 & 1131 & $15.3 \%$ \\
\hline Sicily & 105 & 719 & $14.6 \%$ \\
\hline Lazio & 225 & 1693 & $13.3 \%$ \\
\hline Sardinia & 39 & 297 & $13.1 \%$ \\
\hline Molise & 12 & 97 & $12.4 \%$ \\
\hline Apulia & 72 & 673 & $10.7 \%$ \\
\hline Basilicata & 15 & 147 & $10.2 \%$ \\
\hline Calabria & 28 & 333 & $8.4 \%$ \\
\hline Tuscany & 58 & 744 & $7.8 \%$ \\
\hline
\end{tabular}

Note: The list considers operations authorised by the SME Guarantee Fund before 1 January 2020, and their status as of 31 March 2020 (as most lending agreements take a few weeks to be finalised after the public guarantee is obtained).

Source: OECD Trento Centre elaboration on Italian Business Registry data. 
Overall, 49 innovative firms in South Tyrol obtained on average approximately EUR 442000 each through this scheme, normally over two distinct operations (the average is 1.8). Although the amount is comparatively high - the third highest in the country - this is just a fraction of the total amount that the guarantee can potentially cover (EUR 2.5 million in guarantees covering up to $80 \%$ of the sum loaned out, i.e. about EUR 3.1 million per start-up).

It would however be misleading not to look to this high uptake into context. Indeed, as shown in Figure 2.6, the rate of innovative start-ups accessing guaranteed loans has a strong positive correlation with GDP per capita in that territory. For Bolzano-Bozen, which has the second highest GDP per capita in Italy (after Milan), we notice how the predicted ratio of access to the fund is placed exactly on the trendline, suggesting that South Tyrol's high access rate "should" be expected based on economic fundamentals.

To level the field, we construct a multiple regression model (Table 2.5) controlling also for other background conditions. This method allows to uncover another variable that is correlated with uptake rates: there is a negative relationship, significant at the $10 \%$ level, with the number of start-ups registered - meaning that, all things equal, more "populated" provinces will tend to see lower adoption rates, possibly because of increased competition.

The over- and under-performance in uptake can now be intended in terms of how much actual values deviate from those predicted from the model. In this respect, South Tyrol's performance changes markedly: as a high income, small-to-mid size population region, the model predicts a very high value of access to the instrument $(34.4 \%)$, which exceeds the observed one by 4.3 points. This means that South Tyrol ranks comparatively quite low $\left(69^{\text {th }}\right)$, below the median Italian province, in terms of the likelihood by local startup to use the National Guarantee Fund. However, Bolzano-Bozen is the only province in this group that actually shows a high observed ratio, which cautions in bundling it with clearly "low performing" areas, such as Tuscany and most of the South.

It can instead be said that, despite its high uptake rate, South Tyrol's fundamentals should imply an extremely high one - the highest in the country by far. Nonetheless, as the $R^{2}$ value from the model shows, access ratios are still mostly explained by unobserved factors, i.e. from the characteristics of registered firms. As it will be shown in Chapter 3, South Tyrolean start-ups are often very small sized, which makes them by default less attractive for credit institutions, thus having a deflationary effect on access rates. 
Figure 2.6. Rate of innovative start-ups that have accessed state-guaranteed bank loans across Italian provinces, and correlation with GDP per capita (January 2020)

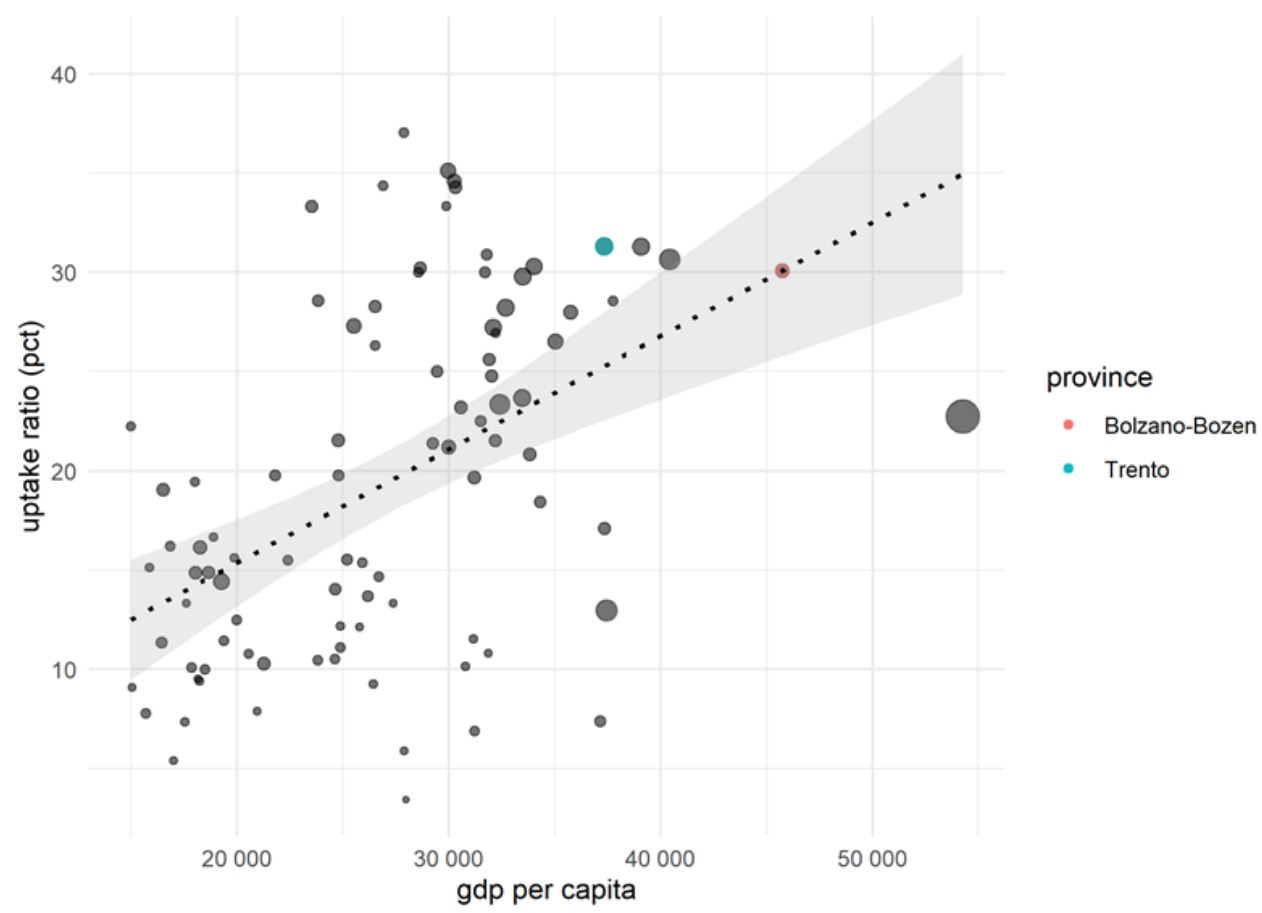

Note: GDP per capita data are for 2017. Only provinces with at least 20 registered start-ups are shown. Source: OECD Trento Centre elaboration on Italian Business Registry and Eurostat data.

Table 2.5. Relationship between rate of innovative start-ups accessing guaranteed loans and GDP per capita, number of registered start-ups, taxable income, provincial level (OLS regression model)

\begin{tabular}{l|r|r|r|r}
\hline & \multicolumn{3}{|l}{ Dependent variable } \\
\hline & \multicolumn{2}{|c}{ Ratio of start-ups beneficiaries of state-guaranteed loans (FGPMI), provincial level } \\
\hline & Estimate & std.error & statistic & \multicolumn{1}{c}{ p.value } \\
\hline Constant & 6.509 & 7.629 & 0.853 & 0.396 \\
\hline Taxable income per capita 2017 & 0.0005 & 0.001 & -0.717 & 0.475 \\
\hline GDP per capita 2017 & 0.001 & 0.000 & 3.155 & $0.002^{* \star *}$ \\
\hline N. registered startups & -0.006 & 0.003 & -1.981 & $0.05^{*}$ \\
\hline & & & & \\
\hline Observations & 103 & & & \\
\hline R-squared & 0.224 & & & \\
\hline Adjusted R-squared & 0.200 & & & \\
\hline Residual standard error & 8.615 & & & \\
\hline F-statistic & 9.517 & & & \\
\hline & & & & \\
\hline
\end{tabular}

Note: Provincial GDP per capita and taxable income data are for 2017. The R-squared value implies that the controlling variables explain around $20 \%$ of the variation in beneficiary start-ups.

Source: OECD Trento Centre elaboration on Italian Business Registry, Eurostat, and Italian Ministry of Economy and Finance data. 
With reference to the Guarantee Fund, policy-makers should also get a better understanding on why, even in the territories with the best uptake rates, normally less than a third of registered firms actually benefit from this instrument. It could also be the case that many start-ups prefer to raise funds exclusively via other channels that are alternative to debt, such as venture capital. In this respect, earlier studies (Giraudo, Giudici and Grilli, 2019 $9_{[30]}$ ) evidenced that companies that raise capital from institutional investors are less propense to apply for guaranteed loans.

\section{Online incorporation}

Start-ups in South Tyrol have made relatively large use of another flagship policy, a digital-based procedure for incorporation introduced in 2016. The measure exempts innovative start-ups from incorporating the company by notarial deed, resulting in lower administrative and consultancy fees. Costs incurred for incorporation constitute a (perceived) major obstacle to firm creation by new entrants: a sample survey conducted by MISE (MISE, 2016, p. 118[37]) estimates that they amount to EUR 2000 on average per new start-up. Conversely, online incorporation implies only limited registration fees ( EUR 250), and the Chambers of Commerce offers free-of-charge assistance at every step of the process. ${ }^{6}$

As an alternative, it is still possible to incorporate start-ups offline through a notarised public deed, the only procedure admitted by law in the past. Indeed, this method is still prevalent across most of Italy, with the propensity to adopt online incorporation varying greatly across regions.

South Tyrol shows a comparatively high uptake rate of this measure: in $2019,44 \%$ of newly incorporated firms had used the online procedure, the $5^{\text {th }}$ highest rate among Italian regions and autonomous provinces. The ratio is over eight points above the national average (36.3\%) and compares favourably to neighbouring Trentino by over 12 percentage points. The rate has increased considerably over time: in 2018, just 27\% of all start-ups had been incorporated online. Although, as shown in Figure 2.7, most regions have seen an increase in uptake of its measure, almost nowhere else this has been as marked as in South Tyrol. 
Figure 2.7. Ratio of innovative start-ups incorporated online over total registered firms incorporated in the year $(2018,2019)$

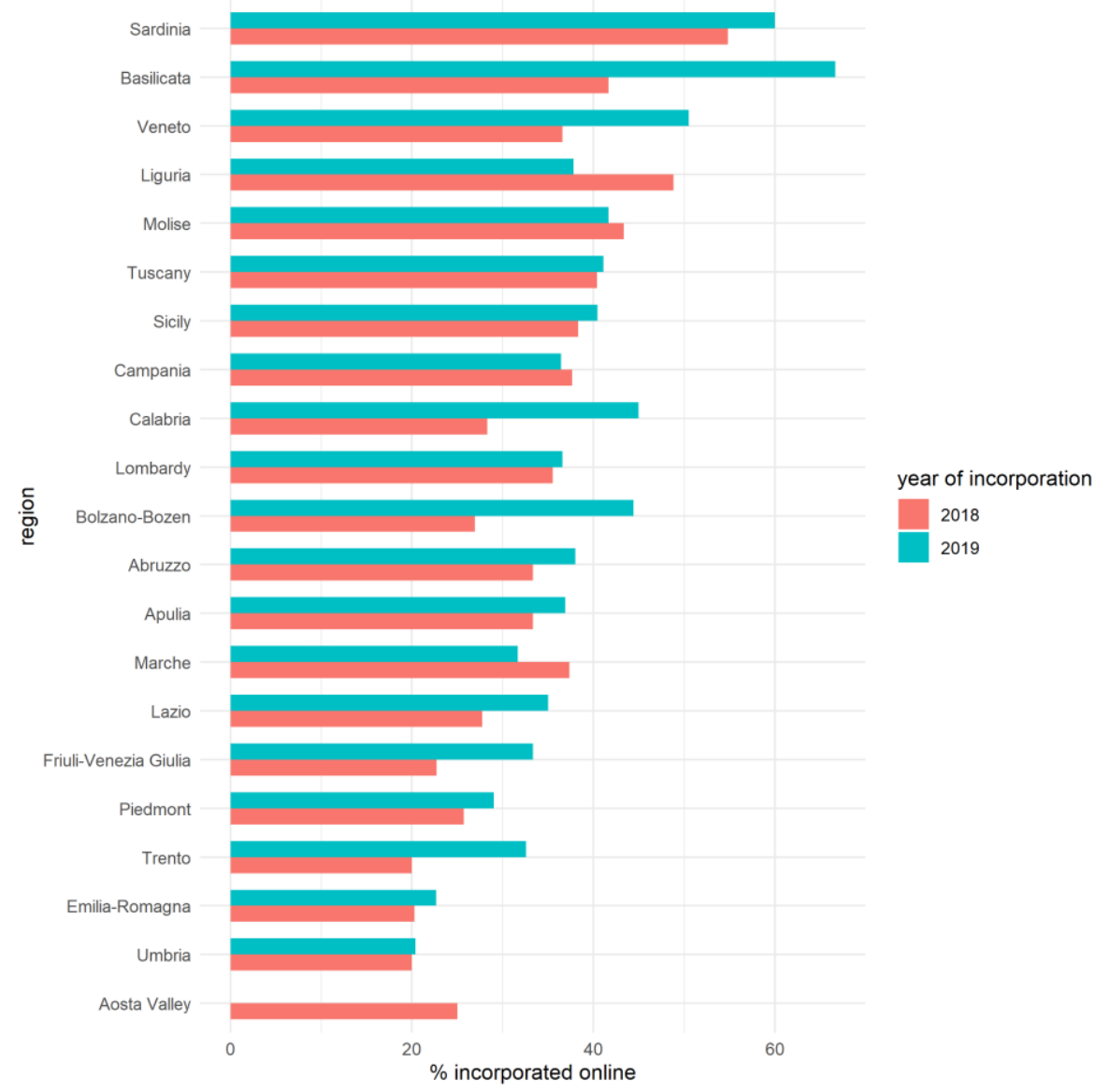

Source: OECD Trento Centre elaboration on Italian Business Registry data.

The stark increase in adoption rates is presumably connected to an improved awareness about the existence and the advantages of this option. The incorporation method is managed by a decentralised body, the bilingual Chamber of Commerce of Bolzano-Bozen, and extensive documentation in German, as well as in Italian, is provided. The availability of legal support in the local language is particularly important, as professionals are known to play key role in spreading information about this initiative. The first and to date only "census" survey of innovative start-ups, performed in early 2016, evidenced how accountants and other tax and law consultants played a major part in disseminating information on benefits and rights connected to innovative start-up status (ISTAT, MISE, 2018[39]), confirming the important advisory role of professional networks (OECD, 2011 [40]).

\section{Online showcase startup.registroimprese.it}

From 2019, the law requires innovative start-ups to complete a public "company profile" on a national platform administered by the Chambers of Commerce. ${ }^{7}$ In addition to open access administrative data drawn by default from the Business Registry, start-ups must add specifics on their innovative potential, the stage of development of their product or service, the key skills of their team members, and more.

South Tyrolean start-ups seems particularly inclined to use this option. As of May 2020, a virtual totality $(95.6 \%)$ of registered start-ups in South Tyrol had filled their profile, the highest rate among Italian regions. 
Indeed, at the national level just seven start-ups in ten had done so $(70.1 \%)$. This is all more remarkable as many local start-ups were not required to fill out the profile until late June 2020 (some even to 2021), meaning that local firms have proved to be highly responsive to changes to the legal framework. Anecdotal evidence suggests that the uptake of this specific measure is to some extent a function of dynamism by the local Chamber of Commerce in raising awareness on new procedures and opportunities involving startups: this confirms the importance that intermediate actors, being them institutions or professionals, have in promoting transfer and uptake of the Italy's start-up policy.

\section{Notes}

${ }^{1}$ Historical "province", which are a conventional statistical unit for large area statistics in Italy, albeit they have often no longer administrative significance. We use the subdivision adopted by Italian Chambers of Commerce, which does not differentiate between province autonome, province and città metropolitane, nor takes into account most recent administrative developments (since the mid-2000s, in some regions provinces have been redesigned or replaced by lower-level large area units).

${ }^{2}$ As per Article 116 (par. 1-2) of Italy's Constitution, Trentino and South Tyrol jointly form the regione autonoma of Trentino-Alto Adige/Südtirol (TAA/S). However, uniquely in Italy, the Statuto d'Autonomia of TAA/S (1972) delegates most of the legislative powers usually attributed to regions to the two province autonome of Trento and Bolzano-Bozen. This asymmetric status (a second-level unit with the powers proper of a first-level division) is also acknowledged by more recent amendments to the national Constitution.

${ }^{3}$ The ratio is calculated as (percentage of share capital held by women + percentage of leading positions held by women $) / 2>50 \%$.

${ }^{4}$ Istat. Tasso di occupazione: Dati regionali (2019).

${ }^{5}$ Some of these schemes, such as Smart\&Start Italia, are run by national agencies. This initiative is targeted exclusively to innovative start-ups, which can be funded through zero-rate loans between EUR 150000 and 1.5 million. Start-ups based in the South of Italy can get up to $20 \%$ of the amount as a non-repayable grant. Other major initiatives targeted to start-ups in the South - not necessarily innovative - include "Resto al Sud", a EUR 1.2 billion scheme of micro-funding (up to EUR 50000 per entrepreneur), part guarantees and part outright grant, primarily aimed to young entrepreneurs based in Southern Italy or willing to relocate there.

${ }^{6}$ For an overview of the registration process, check the guide published by InfoCamere [Italian]: http://startup.infocamere.it/atst/guidaCostitutivo. Last access: 20/05/2020.

${ }^{7}$ URL: http://startup.registroimprese.it/isin/home. The platform can also be browsed in Italian and English. 


\section{Growth trends of innovative start-}

\section{ups}

The Italian Start-up Act is designed to support tech firms in the earliest stage of their life cycle. As outlined in the introduction, beneficiaries are always less than five years old, and legal facilitations will cease to apply as soon as their sales cross EUR 5 million per year. It should therefore not be surprising that the overwhelming majority of registered innovative start-ups can be classified as "micro-SMEs", which in European legislation identifies firms that have a yearly turnover under EUR 2 million, and less than 10 employees. ${ }^{1}$

The most recent data for turnover, which cover the 2018 fiscal year, ${ }^{2}$ show that $99.3 \%$ of innovative startups registered as of 1 January 2020 at national level either qualified as micro-SMEs, or had not filed accounts in 2018 (the average registered start-up is just 736 days old). In other words, just 71 start-ups out of 10901 registered firms had a turnover above EUR 2 million for that year.

This section will first provide a snapshot of how start-ups in Trentino were distributed in terms of turnover, and how they compared to the national average at the onset of 2020. Another key measure of firm size, employment, presents specific challenges for innovative start-ups, which are elaborated in Box 3.1.

An analysis of dynamics will follow, in order to grasp growth trends of beneficiaries, even after the start-up phase. The perspective will be broadened in terms of both time - looking at turnover shifts/variations over several years - and population, by including companies that have been innovative start-ups in the past but that are no longer registered at the reference date. Crucially, the latter comprehend both top-performing firms (i.e. whose turnover exceeded EUR 5 million) and those that have since shut down, enabling a preliminary analysis of scaling-up and exit rates.

\section{Descriptive statistics: a snapshot as of January 2020}

In 2018, the average innovative start-up in South Tyrol placed on the market goods or services for slightly more than EUR 61000 . This value, which refers to $73.9 \%$ of firms registered at the beginning of $2020,{ }^{3}$ is comparatively very low: the national average is above EUR 200 000, and among Italian regions only Sardinia, with 55000 , is further behind. Although, as said, most innovative start-ups in Italy are microenterprises, registered firms in Bolzano-Bozen are particularly small, as evidenced by a median turnover value of just EUR 18 812, the fourth lowest in Italy. Curiously, there are few firms that record a turnover equal to zero ( $7.4 \%$ of all valid values), meaning that most firms in this territory are economically active, even if they often record sales close to nil (Table 3.1). 
Table 3.1. Turnover of registered innovative start-ups in South Tyrol, summary statistics and comparison with Italy at large (2018 fiscal year, EUR)

\begin{tabular}{l|c|c|c|c}
\hline & South Tyrol & $\begin{array}{c}\text { Ranking by } \\
\text { province } \\
\text { (out of 106) }\end{array}$ & $\begin{array}{c}\text { Ranking by } \\
\text { region } \\
\text { (out of 21) }\end{array}$ & Italy \\
\hline Start-ups & 92 & 32 & 19 & 10901 \\
\hline Share of start-ups with valid turnover in 2018 & $73.9 \%$ & 23 & 3 & $64.0 \%$ \\
\hline Mean & 61067 & 88 & 20 & 173199 \\
\hline Median & 18811.5 & 76 & 18 & 33809 \\
\hline Share with turnover = 0 (valid values only) & $7.4 \%$ & 20 & 3 & $13.8 \%$ \\
\hline 95th percentile & 196977 & 90 & 21 & 777866 \\
\hline
\end{tabular}

Source: OECD Trento Centre elaboration on Italian Business Registry Data (financial statements 2018).

Registered start-ups seem therefore much smaller in South Tyrol than in the rest of Italy, as a whole and even when peak values are considered. Just 5\% of start-ups had a turnover above EUR 200000 in 2018 - the $95^{\text {th }}$ percentile is the lowest in Italy - and the highest performing firm just barely crossed EUR 500 000. This means that all currently registered innovative start-ups are micro-SME from a legal standpoint.

Descriptive statistics on currently registered firms are not enough to grasp "peak values", as the bestperforming start-ups (i.e. former start-ups that exceeded EUR 5 million in turnover), together with established firms more than five years old, had left the policy by the date of this analysis. Indeed, values concerning former start-ups are somewhat more encouraging than those on currently registered companies, even if still well below the national level, and there are also a few case of "millionaire" startups. However, just two of them cross the EUR 2 million threshold that identifies micro-SMEs (Table 3.2).

Table 3.2. Turnover of innovative start-ups in South Tyrol, key peak values for currently and formerly registered firms, comparison with the rest of Italy (2018 fiscal year, EUR)

\begin{tabular}{|c|c|c|c|c|}
\hline & \multicolumn{2}{|c|}{ South Tyrol } & \multicolumn{2}{|c|}{ Italy } \\
\hline Registered & Former & Current & Former & Current \\
\hline Mean & 314972 & 61067 & 646029 & 173199 \\
\hline Median & 50000 & 18811.5 & 131036 & 33809 \\
\hline $95^{\text {th }}$ percentile 2018 & 1917450 & 196977 & 2444663 & 777866 \\
\hline Share of non-micro SMEs ${ }^{4}$ & $1.5 \%$ & $0.0 \%$ & $1.7 \%$ & $0.7 \%$ \\
\hline Highest value 2018 & 2371161 & 547345 & 168133941 & $7798006^{5}$ \\
\hline
\end{tabular}

Source: OECD Trento Centre elaboration on Italian Business Registry Data (financial statements 2018). 


\section{Box 3.1. Innovative start-ups' employment conundrum}

A comprehensive analysis of growth trends should also take into account employment generated by beneficiary firms. Unfortunately, available Business Registry data do not allow a precise analysis in this respect.

The size of the labour force of Italian innovative start-ups is not well known. Data from INPS, the national social security authority, only takes into account individuals hired on a dependent contract. Table 3.3 shows key statistics about the distribution of such employees. As of 1 January 2020, MISE and InfoCamere reported a total of 14324 employees among Italian innovative start-ups. A majority of registered firms did not report any.

This number is widely seen as an underestimation. Most of the labour force of start-ups, especially in their early stage, does not appear in the books as employees, but as shareholders. Their number is known and regularly published by MISE and InfoCamere, which state in their reporting that start-ups "involve" around 65000 individuals. However, there is no information to tell what percentage of shareholders are actually involved in daily operations of the company, as opposed to mere investors.

Furthermore, neither employee nor shareholder data grasp another important side of start-up workforce: consultants, freelancers, and workers in the gig economy - which, given the high density of software development firms and online platforms, arguably play a major part. The only study carried out on this aspect to date (ISTAT, MISE, 2018, p. $33_{[39]}$ ) evidenced how about $25 \%$ of all innovative start-ups employ interim staff; in this group, one third of firms do not have any permanent personnel.

Table 3.3. Distribution of employees of registered innovative start-ups in South Tyrol and Italy (January 2020)

\begin{tabular}{l|r|r}
\hline & South Tyrol & Italy \\
\hline Share of firms with more than one employee & $47.8 \%$ & $40.1 \%$ \\
\hline Mean* & 1.8 & 3.5 \\
\hline Median* & 1 & 2 \\
\hline $95^{\text {th }}$ percentile & 4.7 & 11 \\
\hline Max & 7 & 234 \\
\hline
\end{tabular}

Note: * Only companies with at least one employee are considered.

Source: OECD Trento Centre elaboration on Italian Business Registry Data.

\section{Visualising growth trends over time: a cohort-based analysis}

The present section examines the annual variations of start-ups' turnover values since registration. The behaviour of South Tyrol's start-ups is compared to Italy's registered firms as a whole. The analysis takes into account all innovative start-ups ever registered, and allows to capture growth trends even after losing this particular legal status: firms in each cohort may or may not have left the special directory during the observation period, and some will have ceased operations by the end of the reference period.

Our methodological approach is to break down the start-up population into two distinctive cohorts, based on the year they joined the policy. Although start-up population varies sharply in different regions, this choice allows to obtain subsamples of acceptable size across most of Italy, facilitating transferability of the same methodology. 
"Early adopters" include firms that joined the policy shortly after its inception, i.e. they registered as innovative start-ups in 2013 and 2014. For these firms, the analysis of turnover trends extends over a period of five years, from 2014 to 2018. As shown in section 2.2, this population is very small in South Tyrol, counting 22 firms overall. The second cohort covers firms registered in 2015 and 2016, which were breakthrough years in most of Italy in terms of new registrations. These firms are followed across a period of three years (2016-2018). In Bolzano-Bozen, this cohort counts 60 firms, which constitutes a more meaningful sample size for a comparison. ${ }^{6}$

Moreover, it must be noted that most of the measures that make up the Italian Start-up Act came into force gradually over time (MISE, 2017[41]), with some key measures not being fully accessible until 2015 or $2016 .{ }^{7}$ The potential impact of the policy on survival and growth rates is thus expected to be all the more significant the more recent the date of entry.

In the following, turnover trends are visualised in increasing detail. In the first part, descriptive tables will show changes in the relative weight of turnover classes across the years. Secondly, a dynamic analysis visualises year-by-year flows across these classes. Finally, a two-way plot presents variation in turnover values between the first (x-axis) and the end year (y-axis) of the observation period for each start-up in the cohort.

\section{Size of turnover classes}

Table 3.4 and Table 3.5 show respectively how South Tyrol's "early adopter" and "second wave" innovative start-ups distribute, in each year between 2014 and 2018, across five turnover classes, ranging from startups with very low yearly turnover values (under EUR 50000 per year) to the few that cross the EUR 5 million mark ${ }^{8}$. Specific classes are displayed for start-ups no longer in operations (shutdowns), ${ }^{9}$ for those that were about to close shop (winding up), ${ }^{10}$ and those for which the turnover values are missing and no inferences could be made (NA).

As evidenced in the earlier paragraph, most start-ups registered into the policy in this region are very small enterprises. In both cohorts, just a handful of firms come to register turnover values above EUR 500000 by the end of the reference period. This is particularly remarkable for second wave start-ups: while normally in Italy about $10 \%$ of companies in a given cohort manage to overcome that threshold by their third year of registration, in Bolzano-Bozen just one firm (a "millionaire" start-up) does so. Exit rates are also somewhat high, particularly if we take into account the fairly large number of missing values - which can be proxy of a company in the process of winding up.

The fact that there are just a handful of high-growth start-ups is however consistent with national patterns, as "millionaire" firms rarely represent more than $5 \%$ to $7 \%$ of all firms in each cohort: in a small region like South Tyrol this means just one of two firms per cohort. While a strong "middle class" of firms with turnover above EUR 500000 is almost entirely missing, there is a decent concentration in the class immediately below, which is somewhat similar to what is observed in neighbouring Trentino. However, a closer inspection of the database shows - as hinted by summary statistics in the previous paragraphs - that these firms also tend to exhibit lower values than their peers in the neighbouring province. 
Table 3.4. Turnover growth of innovative start-ups in South Tyrol and Italy, shares of start-ups by turnover class over time - early adopters (2014-2018)

\begin{tabular}{|c|c|c|c|c|c|}
\hline South Tyrol & Class 2014 & Class 2015 & Class 2016 & Class 2017 & Class 2018 \\
\hline Shutdown & $9.1 \%$ & $9.1 \%$ & $13.6 \%$ & $18.2 \%$ & $22.7 \%$ \\
\hline Winding up & $68.2 \%$ & $50.0 \%$ & $36.4 \%$ & $27.3 \%$ & $18.2 \%$ \\
\hline Below EUR 50000 & $9.1 \%$ & $18.2 \%$ & $27.3 \%$ & $22.7 \%$ & $27.3 \%$ \\
\hline EUR $50000-500000$ & $4.5 \%$ & $9.1 \%$ & $4.5 \%$ & $4.5 \%$ & $4.5 \%$ \\
\hline EUR 500 000-1 million & $0.0 \%$ & $4.5 \%$ & $9.1 \%$ & $13.6 \%$ & $9.1 \%$ \\
\hline EUR 1 million-5 million & $4.5 \%$ & $4.5 \%$ & $0.0 \%$ & $0.0 \%$ & $0.0 \%$ \\
\hline EUR above 5 million & $4.5 \%$ & $4.5 \%$ & $9.1 \%$ & $13.6 \%$ & $18.2 \%$ \\
\hline NA & $9.1 \%$ & $9.1 \%$ & $13.6 \%$ & $18.2 \%$ & $22.7 \%$ \\
\hline Italy & Class 2014 & Class 2015 & Class 2016 & Class 2017 & Class 2018 \\
\hline Shutdown & $1.5 \%$ & $4.3 \%$ & $8.6 \%$ & $13.2 \%$ & $18.2 \%$ \\
\hline Winding up & $0.8 \%$ & $1.5 \%$ & $1.7 \%$ & $1.9 \%$ & $0.0 \%$ \\
\hline Below EUR 50000 & $54.0 \%$ & $39.2 \%$ & $30.2 \%$ & $25.8 \%$ & $17.4 \%$ \\
\hline EUR $50000-500000$ & $29.1 \%$ & $40.5 \%$ & $39.2 \%$ & $33.2 \%$ & $29.2 \%$ \\
\hline EUR 500 000-1 million & $2.8 \%$ & $4.6 \%$ & $5.2 \%$ & $6.5 \%$ & $6.6 \%$ \\
\hline EUR 1 million-5 million & $2.4 \%$ & $3.7 \%$ & $5.2 \%$ & $5.9 \%$ & $6.8 \%$ \\
\hline EUR above 5 million & $0.1 \%$ & $0.2 \%$ & $0.4 \%$ & $0.8 \%$ & $1.2 \%$ \\
\hline NA & $9.3 \%$ & $6.0 \%$ & $9.4 \%$ & $12.7 \%$ & $20.6 \%$ \\
\hline
\end{tabular}

Source: OECD Trento Centre elaboration on Italian Business Registry Data.

Table 3.5. Turnover growth of innovative start-ups in South Tyrol and Italy, shares of start-ups by turnover class over time - second wave (2016-2018)

\begin{tabular}{l|r|r|r}
\hline South Tyrol & Class 2016 & Class 2017 & \multicolumn{1}{r}{ Class 2018 } \\
\hline Shutdown & $3.3 \%$ & $6.7 \%$ & $13.3 \%$ \\
\hline Winding up & $3.3 \%$ & $6.7 \%$ & $0.0 \%$ \\
\hline Below EUR 50 000 & $61.7 \%$ & $43.3 \%$ & $31.7 \%$ \\
\hline EUR 50 000-500 000 & $18.3 \%$ & $25.0 \%$ & $28.3 \%$ \\
\hline EUR 500 000-1 million & $1.7 \%$ & $1.7 \%$ & $0.0 \%$ \\
\hline EUR 1 million-5 million & $1.7 \%$ & $1.7 \%$ & $1.7 \%$ \\
\hline EUR above 5 million & $10.0 \%$ & $15.0 \%$ & $25.0 \%$ \\
\hline NA & $3.3 \%$ & $6.7 \%$ & $13.3 \%$ \\
\hline Italy & Class 2016 & Class 2017 & 2018 \\
\hline Shutdown & $1.7 \%$ & $4.6 \%$ & $8.9 \%$ \\
\hline Winding up & $1.0 \%$ & $1.7 \%$ & $0.0 \%$ \\
\hline Below EUR 50 000 & $53.3 \%$ & $40.7 \%$ & $28.5 \%$ \\
\hline EUR 50 000-500 000 & $27.0 \%$ & $32.1 \%$ & $29.8 \%$ \\
\hline EUR 500 000-1 million & $3.2 \%$ & $5.3 \%$ & $6.1 \%$ \\
\hline EUR 1 million-5 million & $2.0 \%$ & $3.7 \%$ & $5.1 \%$ \\
\hline EUR above 5 million & $0.3 \%$ & $0.4 \%$ & $0.6 \%$ \\
\hline NA & $11.5 \%$ & $11.5 \%$ & $21.0 \%$ \\
\hline
\end{tabular}

Source: OECD Trento Centre elaboration on Italian Business Registry Data.

\section{Dynamic analysis}

The descriptive analysis above hints at movement between the classes over time. It is intuitive, for instance, how the two smallest turnover classes - and the smallest in particular - are gradually shrinking due to an increasing number of shutdowns and higher turnover values.

The flows between turnover classes can be visualised through an alluvial diagram (also known as a "Sankey chart"). Figure 3.1 and Figure 3.2 give dynamism to data in the table above, showing the extent to which companies in each class have transitioned to another class in the following year. 
Figure 3.1. Flows between turnover categories of innovative start-ups in South Tyrol (left) and in Italy (right), early adopters (2014-2018)
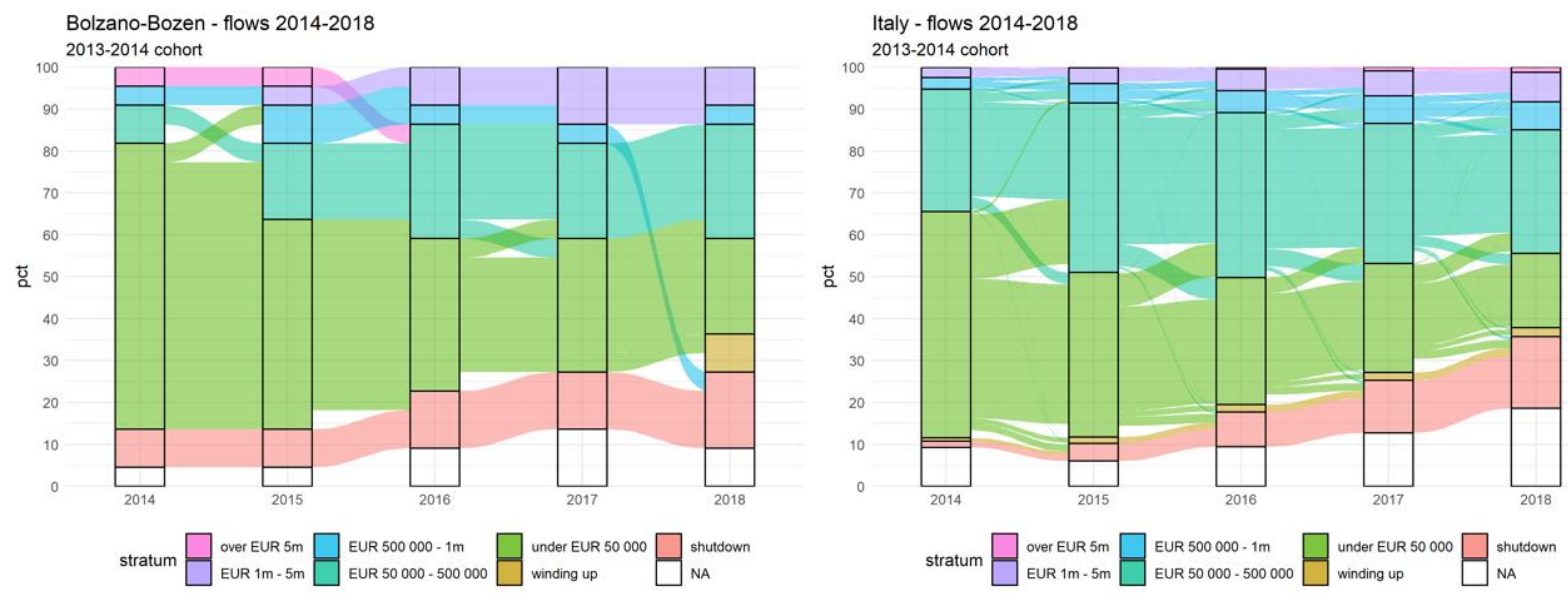

Note: Created in $\mathrm{R}$ with the ggalluvial package.

Source: OECD Trento Centre elaboration on Italian Business Registry Data.

Figure 3.2. Flows between turnover categories of innovative start-ups in South Tyrol (left) and in Italy (right), second wave start-ups (2016-2018)
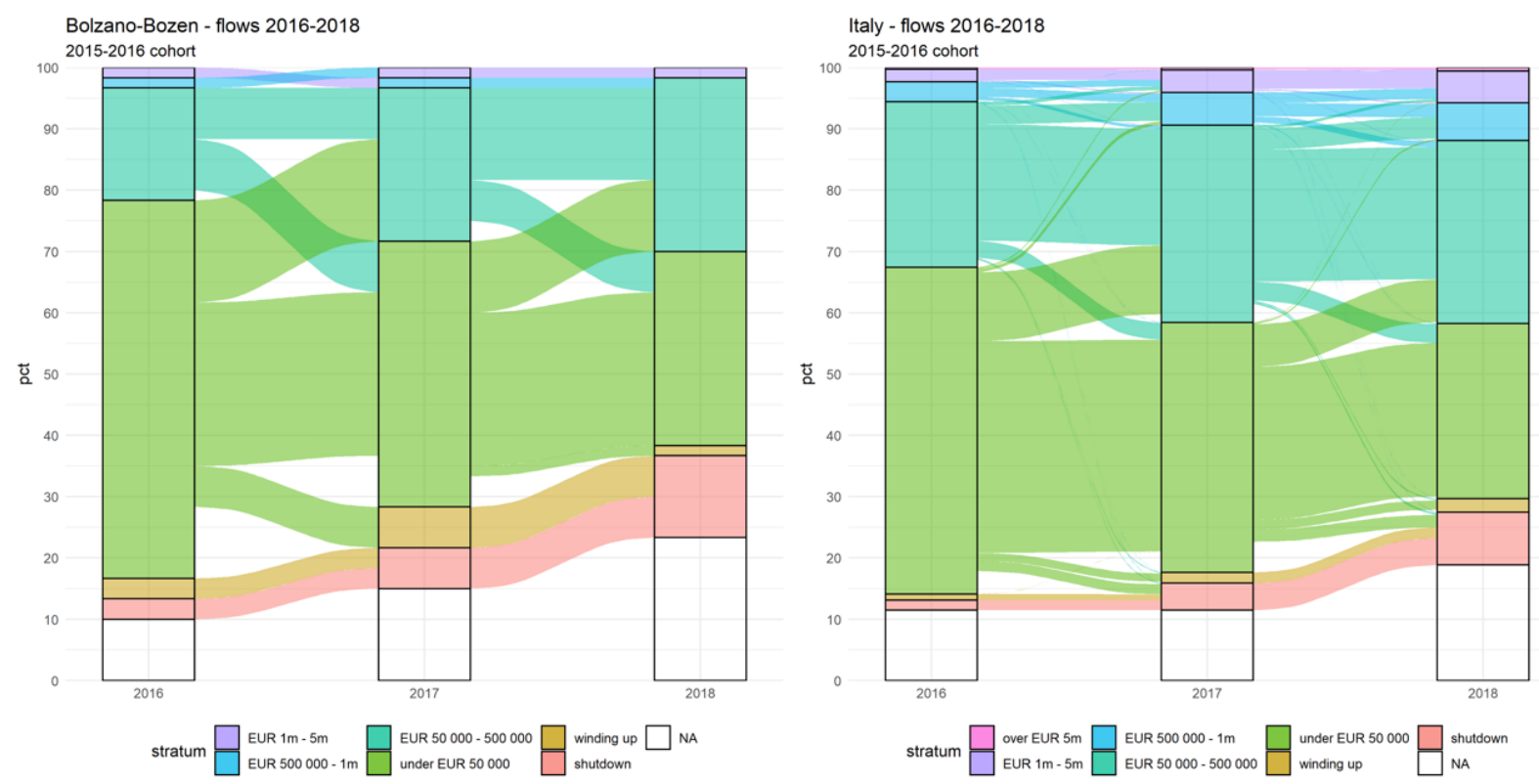

Note: Created in $\mathrm{R}$ with the ggalluvial package.

Source: OECD Trento Centre elaboration on Italian Business Registry Data.

Graphs show that a fair share of start-ups in both cohorts are actually rather stationary across the years. For example, $43 \%$ of firms in the younger cohort that had a turnover under EUR 50000 in 2016 were still under that threshold in 2018. For the older cohort the rate is however much smaller, as most firms in that classes had transitioned to higher levels by 2018. In general, the graphs give an intuitive impression that start-ups grow during their stay in the registry, although fast scaling-up is rare - in South Tyrol there is just one recorded case of transition from the lowest class to millionaire status. Another common pattern, 
besides a few "quirks", is that firms that shut down are almost always firms that have never had meaningful turnover values. Similar trends all around Italy suggest that the overwhelming majority of innovative startups that ceased their activity had never found validation on the market.

\section{Focus on individual growth trajectories}

The small population of start-ups in each cohort in South Tyrol makes indeed possible to glance at the growth trajectory followed by every firm in the sample. This can be done by means of a bivariate scatterplot, turning turnover values into coordinates and showing each start-up as a point on a grid.

Figure 3.3 and Figure 3.4 show that innovative start-ups in Bolzano-Bozen normally grow since the first year in the policy: almost all points are located to the left of the diagonal line that indicates a stationary state - i.e. identical turnover values at the beginning and the end of the observation period. There is a difference between the two plots: for the older cohort, most start-ups with meaningful turnover levels tended to have fairly low values in their first year. For the younger cohort, start-ups that perform better were more likely to record measurable sales already in their first year of registration, which is testified by their relative proximity to the diagonal line that represent equality of $x$ and $y$ values.

Figure 3.3. Individual growth trajectories of start-ups in South Tyrol, early adopters (2014-2018)

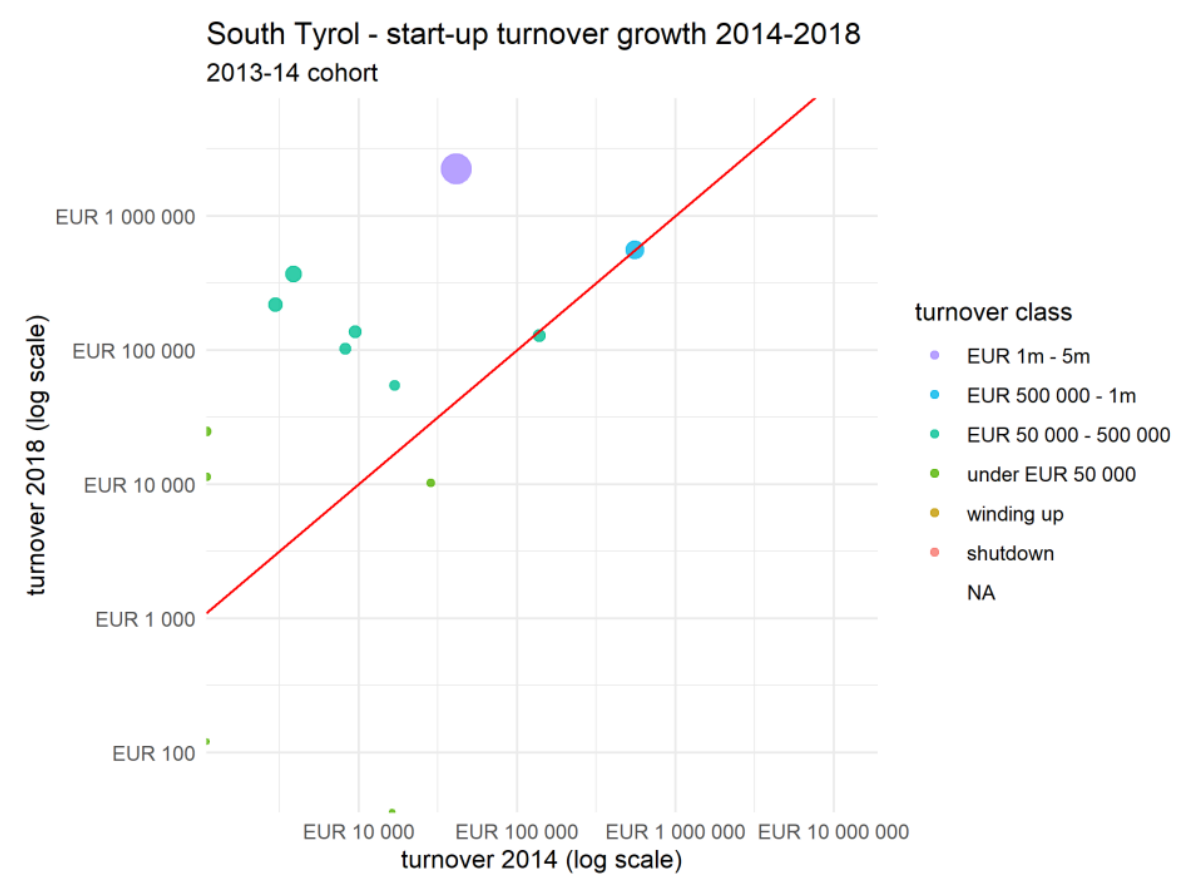

Note: The $x$ and $y$ axes are logarithmic $(\log 10)$. Forty-four shutdown firms with no turnover value in 2018 are not shown. Source: OECD Trento Centre elaboration on Italian Business Registry Data. 
Figure 3.4. Individual growth trajectories of start-ups in South Tyrol, second wave (2016-2018)

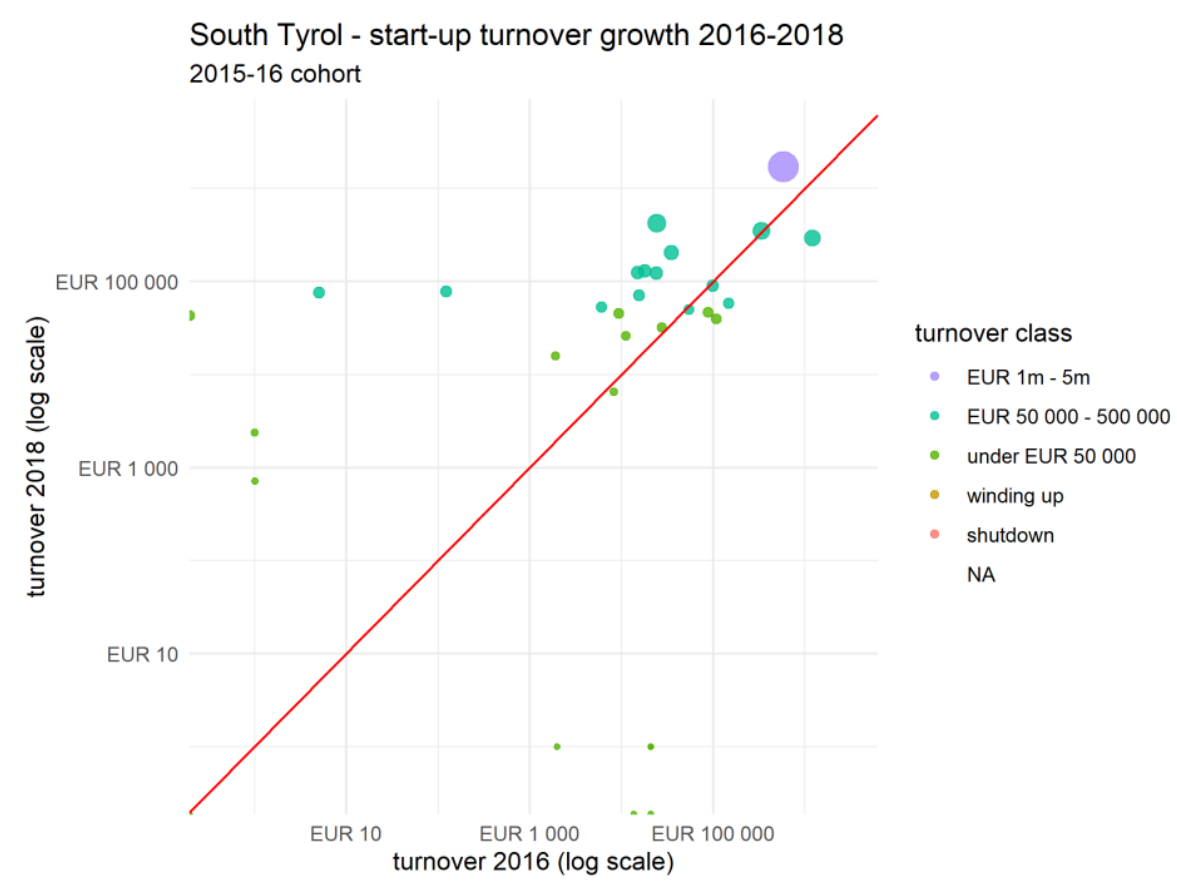

Note: The $x$ and $y$ axes are logarithmic (log10). Forty-four shutdown firms with no turnover value in 2018 are not shown. Source: OECD Trento Centre elaboration on Italian Business Registry Data.

\section{Discussion of findings}

The growth trends of South Tyrol's start-ups during and after the period of public support were analysed in the previous sections.

Findings seem unambiguous: innovative start-ups in South Tyrol are, with a few exceptions, very small firms. The typical registered (and formerly registered) start-up is smaller than the national average and much smaller than in neighbouring Trentino, a divergence that is amplified by the gap in the number of registered companies. There are almost twice the number of registered start-ups in Trento compared to Bolzano-Bozen, a ratio that is even more lopsided among the firms of the oldest cohort - which, when they survive, normally show fairly high turnover values.

The results of this part of the analysis should be interpreted in the context of the findings presented in Chapter 2, as well as by keeping in mind the broader economic environment of South Tyrol. There are several clues that point to policy transfer issues: among these, a territorial distribution slanted towards Italian-language areas, and a rate of access to guaranteed bank loans that is lower than what macroeconomic fundamentals predict. The latter finding may thus be explained by the fact that most registered start-ups are low-performing, and therefore unappealing customers for credit institutions. However, the very fact that the "gross" uptake rate is so high indicates that framework conditions for entrepreneurship are good.

Likewise, it is plausible that in South Tyrol the policy framework simply fails to capture many promising innovative enterprises, and is thus not unleashing its full potential: a challenge for policy-makers interested in encouraging the competitiveness of the local start-up ecosystem. 


\section{Notes}

1 Small and medium-sized enterprises (SMEs) are defined in the EU recommendation 2003/361. URL: http://eur-lex.europa.eu/legal-content/EN/TXT/?uri=CELEX:32003H0361\&locale=en.

2 Yearly accounts in Italy cover the 1 January-31 December 2018 period, with limited exceptions.

${ }^{3}$ Normally, missing turnover data are due to the fact the firm did not file their financial statements on that year, either because it did not exist yet or because it was exempted from doing so (e.g. because it started to do business very close to the end of the fiscal year). However, there is a significant share of unexplained missing values: as shown in Section 3.2, this amounts on average to about $10 \%$ of all start-ups registered in a given year.

${ }^{4}$ Turnover values only.

${ }^{5}$ In rare circumstances, a start-up can still be registered in the special directory even if it has passed the EUR 5 million threshold: for instance, when it is transitioning to "innovative SME" status or when the administrative process for removal is yet to be completed.

${ }^{6}$ In all of Italy, 3188 start-ups are classified in the first cohort ("early adopters"), while 4528 are part of the "second wave".

7 The preferential track to the SME Guarantee Fund was enabled in late 2013, and the Smart\&Start Italia subsidised finance programme was extended to all of Italy in 2015. Online incorporation entered into force in mid-2016, while tax incentives for equity investors are accessible at the current rate $(30 \%)$ only since 2017.

${ }^{8}$ In rare circumstances, a start-up can still be registered in the special directory even if it has passed the EUR 5 million threshold: for instance, when it is transitioning to "innovative SME" status or when the administrative process for removal is yet to be completed.

${ }^{9}$ Normally shutdown firms do not file statements of account in the year when they cease their activity. In the few instances they do, the value is discounted.

10 This category identifies the start-ups that have not submitted a statement of account in that year, and that have formally ceased business in the following year. 


\section{Breakdown by economic sector: "traditional" areas and emerging technologies}

\section{"Traditional" NACE classification of start-ups (and its shortcomings)}

The definition of innovative start-up adopted in Italy does not entail any explicit sectorial limitation. ${ }^{1}$ Provided that the firm introduces a component of "technological innovation" in its business model, as stated by its objects clause and ascertained by the fulfilment of measurable innovation requirements (see section 1.2 ), it can be admitted into the start-up registry regardless of its economic sector.

According to the Statistical Classification of Economic Activities in the European Community, commonly referred to as NACE, the dominant economic activity for innovative start-ups in South Tyrol is information technology (42.4\%). The share is however somewhat lower than at Italian level, where ICT start-ups make up almost half of all registered firms; in particular, there is a less pronounced share of firms with the NACE code for "Computer programming" (30.4\% against 35.6\%) - a broad group that includes, among others, most of the app economy. Another very common class in the tertiary sector is "Scientific research and development", which is more common in South Tyrol than in Italy at large $(20.7 \%$ vs $13.9 \%)$. South Tyrol, as neighbouring Trentino, has a higher share than average of manufacturing start-ups: $28.2 \%$ have the corresponding NACE code, over 10 points above Italy's level. Although the very small population size makes inferences difficult, it is remarkable how four registered start-ups in Bolzano-Bozen have a code relating to manufacture of motor vehicles and transport, which are otherwise quite rare at national level. Other economic activities are only residually represented - e.g. there is one innovative start-up in the agricultural sector - or not represented at all, such as wholesale retail and hospitality (Table 4.1).

Table 4.1. Distribution of innovative start-ups by economic activity (NACE), South Tyrol and Italy (January 2020)

\begin{tabular}{l|r|r|r|r}
\hline & South Tyrol & \multicolumn{2}{|c}{ Italy } \\
\hline J 62 - Computer programming & 28 & $30.4 \%$ & 3883 & $35.6 \%$ \\
\hline J - Other ICT & 11 & $12.0 \%$ & 1287 & $11.8 \%$ \\
\hline M 72 - Scientific research and development & 19 & $20.7 \%$ & 1512 & $13.9 \%$ \\
\hline M - Other services & 6 & $6.5 \%$ & 481 & $4.4 \%$ \\
\hline C 27 - Manufacture of electrical equipment & 4 & $4.3 \%$ & 169 & $1.6 \%$ \\
\hline C29/30 - Manufacture of motor vehicles/other transport & 4 & $4.3 \%$ & 139 & $1.3 \%$ \\
\hline C - Other manufacturing & 18 & $19.6 \%$ & 1866 & $17.1 \%$ \\
\hline G - Wholesale and retail trade & 1 & $1.1 \%$ & 370 & $3.4 \%$ \\
\hline A - Agriculture and fisheries & 0 & $0.0 \%$ & 79 & $0.7 \%$ \\
\hline Other & 1 & $1.1 \%$ & 947 & $8.7 \%$ \\
\hline Total & 92 & $100.0 \%$ & 10901 & $100.0 \%$ \\
\hline
\end{tabular}

Source: OECD Trento Centre elaboration on Italian Business Registry Data. 
While this distribution gives a first impression of the structure of South Tyrol's population, it does little to clarify in which ways registered start-ups are indeed innovative. Many NACE codes are arguably too broad - e.g. "computer programming" - and/or devoid of key content - "research and development", "manufacture of machinery and equipment" - to provide useful information on start-up business models. The very app economy mentioned above can involve a highly diversified range of sectors, spanning from car sharing and food delivery to cryptocurrencies and influencer marketing, just to mention a few, but all are likely to be classified within the same NACE code. There are also credible concerns that the sectorial spread may be partly influenced by random chance, with for instance hybrid software-hardware IT startups being alternatively classified as "manufacturing" or "software development", depending on how statutes of incorporation were drafted.

\section{Identifying start-ups that adopt emerging digital technologies: a topic modelling approach}

\section{Rationale and data}

A systematic understanding of the field in which innovative start-ups operate require methods that supplement or replace NACE codes. This is particularly necessary to keep track of new technology and investment trends, and to assess the performance of public policies aimed at "frontier" domains.

The Italian policy-maker has up to now relied on encouraging public "self-identification" from the side of entrepreneurs. These, upon registration of their innovative start-up, are required to fill out a public profile on the startup.registroimprese.it platform (see section 1.3), including by indicating up to three tags to describe their specific activity and therefore signal their belonging to a specific sectorial or technological subgroup. Each firm can freely choose these tags, which often bear no resemblance to traditional classifications and are influenced by the marketing proposition of the start-up. In this way, a company focussing on "machine learning" technology will be able to distinguish itself from others whose NACE code falls under the broader "software development" category.

Specific sectorial information may also be retrieved through standard administrative documentation normally produced by all firms (regardless of their innovative start-up status). Every Italian firm, in its act of incorporation, has a long description of the economic activities it intends to pursue - an "oggetto sociale", "objects clause". This goes along with a shorter description for operational and auditing purposes called "descrizione attività", literally "activity description", which is easier to change (being not part of the statute) and never longer than 200 characters. In a legal opinion, MISE clarified that the activity description is a useful tool to ascertain the "innovation component" of the business, as per the legal definition of start-up. ${ }^{2}$ For this reason, it is likely that this text will describe in detail the type of innovation introduced, "strategically" using sector-specific keywords. This last feature makes this source particularly suited for a text analysis exercise. In the dataset used for this section, South Tyrol hosts 88 registered start-ups, four less than three months earlier.

\section{Methodology: topic modelling}

Topic modelling is a form of unsupervised machine learning. It is normally used in natural language processing to cluster together similar documents, part of a wider corpus. The innovative start-up directory can thus be understood as a corpus of documents, which in this case are the activity descriptions of each registered start-ups.

The power of topic models is that they make it possible to discover the main themes underlying a corpus of texts without any prior information being fed to them. In this work, this is achieved thanks to a probabilistic algorithm, Latent Dirichlet Allocation, or LDA (Blei, $\mathrm{Ng}$ and Edu, 2003 ${ }_{[42]}$ ). LDA uses the frequencies with 
which words appear in each document to make inferences about unobserved topics that "gave rise" to the use of those words, or in other terms estimates the probabilities that (a) each word and (b) each document are composed of each topic. Resulting probability scores are called beta, for words, and gamma, for documents. They add up to 1.0 within each word or document when all topics are considered, which facilitates their understanding as compositional percentages. ${ }^{3}$

LDA is appealing because, while computationally complex, ${ }^{4}$ it is easy to exploit: to fit the model, the researcher must only decide in advance the number of topics to look for ("k-value"). This choice is arbitrary, and a "right" number can only be found through an iterative process: that is, trying several values, and checking every time that words have the highest beta score within each topic.

For this paper, we ran an LDA model based on a k-value of 12 . The parameter is sufficient to generate a category in which the five most distinctive words, ranked by beta score, are software, algoritmi ("algorithms"), artificiale ("artificial"), intelligenza ("intelligence"), data. This topic also exhibits high beta scores for words like cloud, modelli ("models"), blockchain, learning, big, machine, and iot, meaning that it does not encapsulate just artificial intelligence, but emerging digital technologies at large (Figure 4.1).

Figure 4.1. Top-10 words by beta score in the "emerging digital technologies" topic (LDA topic model, k-value $=12$ ), innovative start-ups population (6 April 2020)

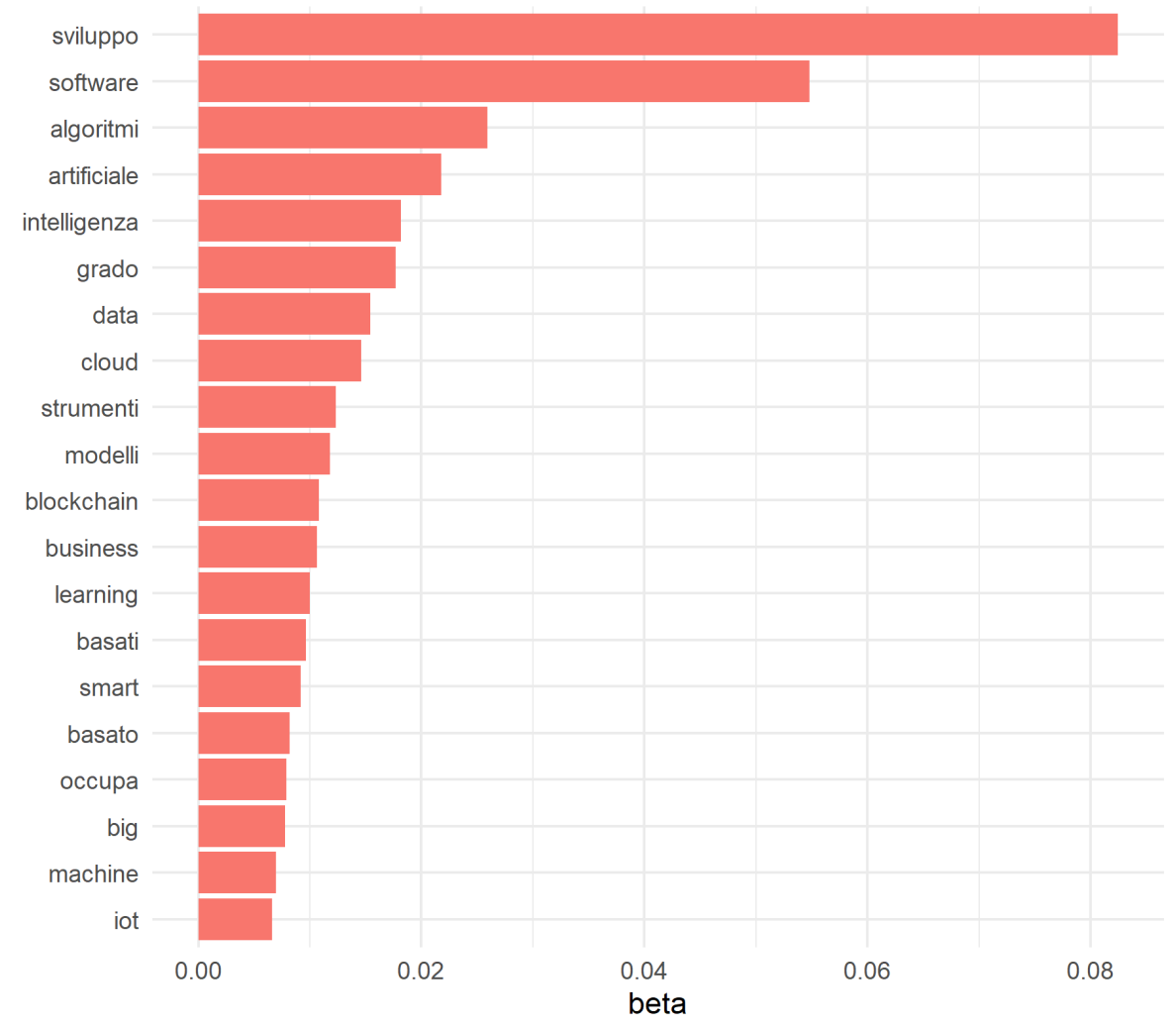

Source: OECD Trento Centre elaboration on Italian Business Registry Data.

Moving from words to documents, i.e. from beta to gamma scores, we observe that the values generated at company level for the emerging digital technologies topic are in a range between 0.286 (maximum) and 0.057 (minimum). The majority of firms have a gamma value between 0.06 and 0.07 , meaning that their "content" in terms of emerging digital technologies is very likely marginal or non-existent. The firms with the highest gamma values are specifically - and beyond any doubt - artificial intelligence start-ups. However, a simple look-up for the words "intelligenza artificiale" shows that firms using them may have 
also somewhat lower gamma scores: these become increasingly uncommon after passing the $95^{\text {th }}$ highest percentile $(0.121)$, and very uncommon only for scores under 0.10 , which is close to the $90^{\text {th }}$ percentile more precisely, $10 \%$ of innovative start-ups have a gamma score higher than 0.107 .

This last specification thus captures almost all companies for which keywords from the desired semantic field (artificial intelligence, big data, references to computational models etc.) are actually present. Using a higher threshold, such as top $5 \%$, actually leaves out a few firms that have very detailed and comprehensive activity description - and which thus includes more words that relate to other topics with a higher probability.

\section{Results}

In short, the LDA machine-learning algorithm identified a topic specifically relating to emerging digital technologies, and assigned gamma scores to each registered start-up based on the likelihood of related words to appear in their activity description. We now define territories as having a high density of "emerging technology" start-ups when the share of firms registered in that area with a gamma score higher than 0.107 is above $10 \%$.

In South Tyrol, 10 registered start-ups have a gamma score for emerging digital technologies higher than the 0.107 threshold, which is $11.4 \%$ of all firms registered as of April 2020 . Bolzano-Bozen ranks $4^{\text {th }}$ out of 21 regions and province autonome in Italy, only behind Lazio, Trento, and Abruzzo (Figure 4.2). The even higher share of Trentino (13.6\%) means that, when we consider Trentino-Alto Adige/Südtirol as a whole unit, it retains the second position among Italian regions (12.9\%). Considering provinces, Bolzano-Bozen ranks $26^{\text {th }}$ of out 106 , and climbs to the $8^{\text {th }}$ place if only those with at least 10 registered firms are considered.

Figure 4.2. Share of registered start-ups adopting emerging digital technologies (top-10 gamma percentile) by region and autonomous province (April 2020)

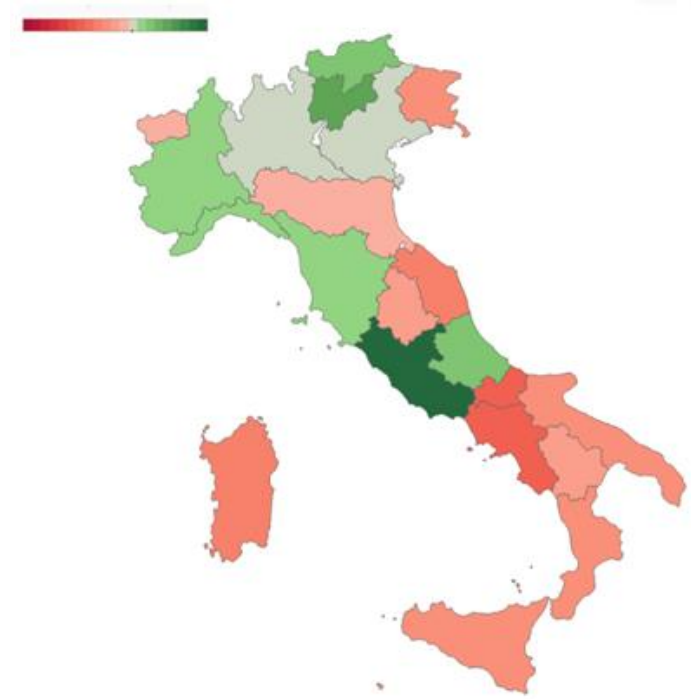

Note: Red shades indicate regions with a share of emerging technology start-ups below $10 \%$. Green shades indicate values above $10 \%$. The darker the shade, the furthest the value is from $10 \%$ in either direction.

Source: OECD Trento Centre elaborations on Business Registry data.

As often evidenced in this work, a small sub-sample size makes wide generalisation difficult. However, South Tyrol exhibits also high mean (0.084) and median (0.079) gamma scores, positioning respectively 
$4^{\text {th }}$ and $3^{\text {rd }}$ among Italian regions. This means that the emerging digital technology component across the whole population is slightly higher than average.

Our analysis shows that Rome is the dominant hub in Italy for innovative start-ups in Al, big data and related fields (18.3\% of all registered). This is primarily a function an extreme concentration of ICT young firms: $60.4 \%$ of innovative start-ups in Rome have the corresponding NACE codes ("J" class). In BolzanoBozen, as earlier said, these firms are less prevalent than in Italy at large (42.4\%), which should have a "deflationary" effect on its overall score. However, ICT start-ups in South Tyrol are about as likely to have a high gamma score for emerging digital technologies as in Rome (21.6\% against $22.4 \%)$, and much likelier than in the rest of the country (14\%). This suggests that the few registered software start-ups in BolzanoBozen adopt more often "frontier" technologies than their peers in most of Italy, and may then be understood as more innovative than average.

To sum up, our exploratory analysis suggests that one of the strengths of South Tyrol's start-up landscape is a relatively high density of innovative firms whose business model exploits emerging digital technologies, which in our framework include artificial intelligence, cloud computing, and advanced computational techniques for big data. This would not have been visible through traditional sectorial classifications, as the share of start-ups in South Tyrol having the NACE codes corresponding to software development is actually fairly low compared to other Italian regions.

This analysis could be made more accurate by running a topic model on less concise, more descriptive text data. Company profiles on startup.registroimprese.it seem ideal, for a number of reasons. First, they have a business rather than administrative purpose, and are therefore more likely to be filled out by entrepreneurs or employees that have a clear grasp of the innovative features of their company, compared to accountants or notaries usually in charge of drafting objects clauses upon incorporation. Second, as evidenced in Section 2.5, virtually the entire population of South Tyrolean start-ups has a full profile on the platform, meaning that there is high potential for performing an accurate mapping. However, the same cannot be said for large swathes of the country, which would make cross-regional comparisons, as that performed in this Chapter, more difficult and less precise.

\section{Notes}

1 The preparatory white paper for the Italian Start-up Act, "Restart, Italia!' (MISE, 2012) spells out the rationale behind this choice: "Intuitively, we can all recognise a startup. We can all recognise an enterprise that has been established recently, one whose goal is to develop, produce and market certain goods or services that are the result of research, or one which uses a high rate of innovation in its activity. We also know that startups do not pertain just to the digital world, but are established across all sectors, including more traditional ones." (p. 10). URL:

https://www.mise.gov.it/images/stories/documenti/startup_eng_rev.pdf [last access: 8 June 2020]

2 Circular issued by MISE on 14 February 2017 (p. 4-5). URL:

https://www.mise.gov.it/images/stories/normativa/Circolare-startup-e-PMI-innovative-14-02-2017.pdf [accessed 5 June 2020]

${ }^{3}$ This explanation is adapted from Catalinac, Amy (2016), "From Pork to Policy: The Rise of Programmatic Campaigning in Japanese Elections". The Journal of Politics, Vol 78, No. 1.

${ }^{4}$ For the specifics, see Blei et al. 2003 or, for beginners to the topic, this guide: "Intuitive Guide to Latent Dirichlet Allocation". URL: https://towardsdatascience.com/light-on-math-machine-learning-intuitive-guideto-latent-dirichlet-allocation-437c81220158 


\section{Main takeaways and policy} recommendations

\section{A language barrier to effective policy transfer?}

This paper offers a novel picture of the innovative start-up landscape in South Tyrol, or more precisely of how Italy's national strategy for high-tech young firms has been adopted in this territory. At a first sight, the province of Bolzano-Bozen seems rather "typical": its ratio between registered start-ups and all new limited companies, $3.4 \%$, is slightly above the national level, $3 \%$. The number of young firms registered into the policy has been roughly constant between 2018 and 2020, meaning that a small but steady flow of new registrations compensate for the number of exits (firms that go bankrupt or lose start-up requirements).

However, there are several hints that South Tyrol is significantly underperforming its potential, meaning that it could have many more start-ups than it currently has. Significant in this sense is the comparison with South Tyrol's immediate neighbour, Trentino. This province can be seen as a suitable counterfactual to South Tyrol, as it is similar to it in many ways. These two areas have shared history, comparable income and employment levels and, perhaps most notably, a similar institutional setup marked by extensive fiscal and legislative autonomy, including competencies in industrial policy. Nonetheless, despite their similarities, Trentino has a very high start-up density $(7.45 \%)$ and over double the number of registered start-ups as South Tyrol, even if the general business population of the latter province is slightly larger (Section 2.1).

The reasons for this divergence are not obvious, but a few hypotheses can be made. The one main difference between South Tyrol and Trentino - as well as with the rest of Italy - is its language makeshift: a majority of South Tyrol residents speak German as first language, while Italian speakers are almost exclusively concentrated in a few large urban centres. There is clear evidence that innovative start-ups tend to agglomerate in main population hubs, and more specifically in areas close to "service provision centres" (higher education institutions, good transport links, etc.): in South Tyrol this trend is very pronounced, whereas the majority of its population lives in small-sized, relatively peripheral municipalities.

When introducing language variation to the equation, it becomes visible how even the largest and better served German municipalities have very few or no registered start-ups; the more easterly and westerly parts of the province, whose population is close to $100 \%$ German-speaking, are also almost completely "empty". Conversely, Bolzano-Bozen and its suburbs, which have an Italian-speaking majority, host over two thirds of all innovative start-ups on the records. Regression analysis at the municipal level shows that there is a significant negative correlation between the number of German-speaking residents and registered start-ups, which holds even after controlling for total population and degree of peripherality (section 2.2).

This analysis is preliminary, but offers already food for thought to policy-makers. There is strong suspicion that the German-speaking community is under-represented among participants in this national policy initiative, although this can only be positively said by checking at entrepreneur level - it is possible that 
German-speakers prefer to incorporate their company in Bolzano-Bozen rather than in their place of residence.

A first plausible factor for this under-representation is that information on Italy's national policy framework for start-ups does not reach out effectively to entrepreneurs, professionals and ecosystem players in the area: that is, there are policy transfer issues. The availability of information resources about the policy in German is scarce: on the official side, it is limited to forms and fact-sheets produced by the bilingual Chamber of Commerce of Bolzano-Bozen, which however still redirects users to Italian-language sources for more detail (e.g. bylaws and legal opinions) (Handelskammer Bozen, 2017[43]). A clue that bilingualism could be influential is the rate of uptake of certain policy instruments that are managed directly at Chamber of Commerce level: innovative start-ups in South Tyrol are comparatively much likely to be incorporated online and to have a profile on the startup.registroimprese.it platform (section 2.4). For both of these operations, entrepreneurs can resort to free-of-charge support by their local Chamber of Commerce, which in South Tyrol means that they can get consulting in German as well. This is in line with survey findings showing that intermediaries, Chambers of Commerce included, play a fundamental part in canalising information about this legal framework to entrepreneurs (ISTAT, MISE, 2018[39]). The obvious recommendation for policy-makers, particularly at the local level, is to ensure full and timely availability of information resources about the policy in either official language. Representative organisation of legal and fiscal professionals should also be involved, by encouraging them to produce independently specialised literature in German.

As an alternative hypothesis, the German speaking community could be less inclined to innovative entrepreneurship compared to Italian speaking peers. This might be the effect of entrenched socio-cultural dynamics, such as historical differences in employment patterns. The trend could also have appeared in more recent times, partly as a consequence of the introduction of the Italian Start-up Act itself: for example, while increasing prominence in Italian mainstream media of the start-up concept might have encouraged more Italian-speaking entrepreneurs to register an innovative firm, German-speakers less exposed to this environment would have not reacted in the same way.

This thesis, at the moment entirely speculative, can only be verified by performing more accurate estimates of the unregistered start-up population. The exercise is highly relevant for national and local administration alike: its execution and follow-up would benefit greatly for the two operating in a synergic way.

It is possible, as done by MISE in 2016, to obtain rough estimates of the number and the distribution of unregistered start-ups by filtering firms in the Business Registry based on legal eligibility criteria: age, turnover, ownership of patents or software. There is also the option to experiment with text analysis techniques. It is possible, as a first step, to measure the proximity of activity descriptions and object clauses of unregistered firms with those of innovative start-ups. However, policy-makers might want to prioritise a measurement of the size of the unregistered population that have the strongest innovation component, or that operate in target sectors - e.g. those identified by local Smart Specialisation Strategies. This objective can be achieved through usage of machine learning techniques, both supervised (i.e. guided by predefined keywords) and unsupervised. For instance, it is possible to replicate a similar approach to that followed in Chapter 4 to identify start-ups adopting emerging digital technologies, running the same algorithm on the entire business population.

An overarching "hunt" for unregistered start-ups based on potential compliance with national criteria can be performed at a centralised level, with cooperation of the data owners - the Italian Chambers of Commerce and their IT in-house firm InfoCamere. Regional development bodies could however play a part in many ways: firstly, thanks to their proximity, they could take care of outreach activities towards unregistered start-ups with characteristics that make them suitable and desirable for public support.

Finally, a third independent hypothesis that might explain a linguistic barrier in policy transfer is that the South Tyrolean ecosystem is less interested to this national policy because its "horizons" are different. Local innovative entrepreneurs may be more inclined to consider opportunities arising in the rest of the 
"Germanosphere", which features one of the most prominent start-up hubs in Europe, Berlin, and other attractive locations such as Vienna. South Tyroleans also commonly take up higher education in a Germanspeaking country: in 2018, there were more students from Bolzano-Bozen enrolled in Austrian universities

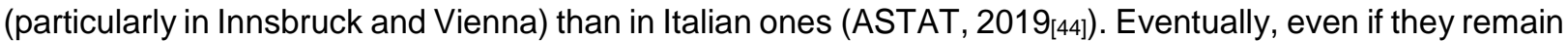
in South Tyrol, entrepreneurs may be more prone to pay attention to developments in Germany or Austria, and to the support opportunities advertised in their first language by the provincial authority.

Local policy-makers could turn this situation to their advantage through a tailored communication strategy. Neighbours in Trento represent a source of inspiration: since 2012, Trentino has sought to promote its preexisting cluster of research institutions and advanced manufacturing firms as a "Start-up Valley", and has then developed several local measures targeted to firms holding innovative start-up status according to the nationally-defined notion. In other words, despite its high degree of autonomy from the central state, in Trentino the nationally defined concept of "innovative start-up" has clearly become embedded in the identity of locally defined industrial strategy. If the policy transfer gap in German-speaking South Tyrol is actually based on cultural milieus, the most effective strategy to pursue is appropriation: local policymakers could advertise the innovative start-up concept as part of a synergic package of locally defined measures. By doing so, they should highlight its benefits as an additional factor of attractiveness for South Tyrol, also as compared with surrounding countries.

\section{High-growth start-ups: is more work needed?}

An analysis of turnover trends has shown that registered start-ups in South Tyrol are very small: the typical beneficiary firm has lower revenues than the national average, and only a handful of firms reaches a meaningful sales volume. In particular, all firms registered into the policy at the reference date were microSME, that is had a turnover of EUR 2 million or less.

Even though start-up "nanism" is more pronounced in South Tyrol - a reason for it may be sub-optimal policy transfer that fails to capture best performing firms, as outlined in section 5.1 - the issue is far from limited to it. Indeed, anywhere in Italy less than $10 \%$ of all innovative start-ups achieve a turnover level of over EUR 1 million by their fifth year of activity: in most territories, this means that there are just a handful of "champions", which is consistent with data emerging from South Tyrol.

As evidenced multiple times in this work, the Italian Start-up Act is primarily conceived to support firms in their very early stages. Several of its measures aim to facilitate the flow of funding towards start-ups, a necessary condition for growth. These are however geared towards micro-funding: an example are tax incentives for risk capital investment. This report has not analysed patterns in access to this instrument, as this information, collected through yearly tax returns, is not publicly available. However, breakdowns by regions and type of beneficiary firm released by MISE $(2016,2017)$ show that the investments covered by the tax benefits are in most cases of very small size (MISE, 2016, pp. 111-117[37])..

The Start-up Act offers more substantial support in terms of debt financing, particularly through the SME Guarantee Fund. As shown in the report, Trentino has the highest rate of access to the instrument in Italy, with about one registered start-up in three having obtained a guaranteed loan. This is significant, as it is not obvious that innovative start-ups would want to resort to debt in their early stages. In fact, they may perceive that this type of finance does not suit their development path. Moreover, given a substantial risk of insolvency, it is personally much riskier for upstarting entrepreneurs. As the OECD (Menon et al., 2018, p. 52[27]) warned in its conclusions, backed by extensive empirical evidence, ${ }^{1}$ debt is a suboptimal form of funding for high-growth innovative start-ups, and no targeted strategy should rely exclusively on it.

Italy has a small venture capital market, which has seen some growth in the last years of the 2010 s - albeit not on the same scale of European partners (Dealroom, 2019 $\left.{ }_{[45]}\right)$. Public policy attempts to attract more VC investments towards Italian firms have so far been unsuccessful; a new National Innovation Fund 
("Fondo Nazionale Innovazione"), which reorganised several initiatives launched in earlier years, was formally set up only in January 2020 (Bria, 2020[46]), and it is not possible to express any judgment on its effects. The OECD evaluation of the Start-up Act stressed that the small size of the Italian VC market may be down to a reputational issue, resulting from long-standing structural inefficiencies such as a slow, cumbersome civil justice system, which makes contract enforcement difficult. The Italian start-up ecosystem, and the significant benefits that its constituents enjoy, is hence not well known to foreign VC investors, and businesses that require substantial capital injections to grow fast are often inclined to relocate in markets perceived as more favourable, such as the United Kingdom or the United States.

It is therefore clear that, alongside the Start-up Act, Italy needs a targeted scale-up strategy. Even if legislation already provides for a "Tier 2" support scheme for PMI innovative, this seems as well not yet sufficient for the necessities of high-growth firms, as it simply extends some of the incentives enjoyed by start-ups to older and larger firms. ${ }^{2}$ This work provides evidence that the main issue for a public policy that supports scale-ups is not extending support beyond the typical start-up age (in Italian law, five years after incorporation): firms that have a high turnover potential tend to show high values already in the first or second year after their registration.

The pace of turnover growth in early years can be used by local policy-makers as an instrument to identify firms that "aim big". As a first step towards an organic scale-up strategy, we encourage them to develop early warning systems for innovations that have potential for success on the market. This can be done also via qualitative measures of innovation and disruption potential, such as those developed by the European Commission in its Innovation Radar qualitative survey on research projects, particularly in the digital field (De Prato, Nepelski and Piroli, 2015[47]).

Promising firms may then become eligible for more advanced forms of mission-oriented support that encourage ambitious investment, experimentation and opening to international markets. Such schemes must have a prominent component of provision of patient capital, also (but not exclusively) via direct participation to share capital. Resources for these scale-up schemes may be diverted from existing measures based on zero-interest loans and deferred payments, which are less likely to select the most innovative project as they are to offer an additional credit line to the entrepreneurs that already have the best resources, and that can for instance obtain more easily loans on the general credit market. As shown in the report, this is primarily dependent on endogenous firm characteristics, but there is a strong influence of other factors, a positive correlation with GDP per capita in particular. Such an approach would help making the general policy strategy more place-conscious, acknowledging that, in countries with large regional disparities, underlying macroeconomic conditions influence the likelihood to access market-based instruments even after public intervention.

\section{Start-ups in high-impact sectors: how to find and support them}

Start-up entrepreneurship is not only desirable because it creates growth and employment: as demonstrated by the COVID-19 crisis, innovative solutions are critical in times of emergency, and help accommodate sudden as well as longer-term cultural and social shifts.

A strategy to support start-up ecosystems cannot have a singular focus on the potential for economic growth of firms: it must also assess their potential to introduce innovations that meet social challenges, in the short as well as in the long term. Systematic ways to measure "social impact" as well as "disruption potential" of firms are however not easy to develop, and thus not readily available to policy makers.

The substantial wealth of data generated by the Italian Start-up Act's monitoring system can alleviate this issue. This paper has proposed a method, based on machine learning techniques, to identify the firms that make use of emerging digital technologies in their business models (artificial intelligence, big data 
modelling, cloud computing). South Tyrol, in particular, has emerged as one of the territories in Italy with the highest density of such firms.

It is important for territories to have a deep knowledge of the existing landscape of firms working with these technologies. Artificial intelligence, digitised manufacturing and cloud computing are attracting growing interest from policy-makers, and increasingly so in Europe. The development of better infrastructure and skills and research capacity, as well as a focus in retain industrial data close to their source, is an explicit objective of many European governments and of the 2020 Industrial Strategy of the European Commission (European Commission, 2020[48]). One of the most discussed topics is the uptake of artificial intelligence solutions in small enterprises, which is expected to be promoted via a network of Digital Innovation Hubs all over the European Union during the 2021-2027 programming period. Other strategies, such as the "Ultra-broadband plan" of the Italian Government, aim at improving basic connectivity infrastructure by bringing high-speed broadband internet to $100 \%$ of Italy's productive units, following a "fibre to the factory" approach. ${ }^{3}$

The same text-based approach can be replicated also to identify other recurring "topics" in start-up activity, such as platform-based digital start-ups, or firms that put ecological sustainability at their core - keywords like "resource efficiency" tend to appear regularly in their activity description. The main limitation of this approach is that its reliance on declaration of intents, rather than on outcome: activity descriptions of startups tell that a company intends to work with a certain technology, but nothing is known about progress and results. Text data obtained via the startup.registroimprese.it platform, which is more detailed and must be updated once a year, could offer a more accurate starting set.

The use of text analysis approaches is recommended to national and local policy makers in order to obtain a more nuanced portrait of the local start-up landscape: it is particularly useful for observing clusters of similar firms that do not arise as the direct result of public policy - e.g. highly innovative firms that are not based in science and technology parks, or supported by recognised incubators and accelerators. However, the promising solutions are unlikely to be identified by algorithms - or, in other words, they most likely require a case-by-case approach. We reiterate the recommendation for ecosystem builders, at the national and even more at the local level, to introduce early warning systems that track high potential innovations at the level of individual firms (or cluster of firms), as well as forms of financial support that allow experimentation, long term planning and ambitious investment.

\section{Diversity in start-up entrepreneurship: what can south Tyrol do better?}

This analysis has unveiled a significant under-representation of women and young people among start-up entrepreneurs. The ratio of start-ups primarily owned or managed by women in South Tyrol is just $8.7 \%$ : this is the lowest ratio in all of Italy, almost five percentage points below national average. For youth the picture is also not particularly rosy, as just $16.3 \%$ of all start-ups are owned by under- $35 \mathrm{~s}$ ( $5^{\text {th }}$ lowest ratio in Italy).

These findings are striking, and at the same time revealing of deeper national patterns, when put into context. The autonomous Province of Bolzano-Bozen has, by some distance, Italy's highest rates of employment among females - almost 3 in 4 women of working age are employed - and youth, in every demographic subset. In other Italian regions with high employment rates, such as Trentino or Friuli-Venezia Giulia, it is also possible to evidence trends similar to South Tyrol, with young and particularly women significantly underrepresented among start-up entrepreneurs. Conversely, the regions where a higher share of start-ups are majority female are particularly diffused in the South of Italy, where only a minority of women are in the workforce. A similar consideration can be made for youth-majority start-ups, albeit in a less pronounced way. 
This counterintuitive trend suggests that public policy matters greatly in determining representation of disadvantaged groups. Southern Italian regions, which are low income and thus receive more funds via European and national cohesion policy, have more leeway to introduce programmes aimed at funding start-ups set up by underrepresented groups, which are even more appealing in areas where credit markets are more constrained. ${ }^{4}$ At the same time, these findings suggest that, when no supplementary incentives are introduced, "risky" innovative entrepreneurship is less palatable for these groups insofar there are other job market opportunities, resulting in a higher number of "missing entrepreneurs". In other words, it can be assumed that in South Tyrol, and in wealthier areas in general, there is a much less prominent component of "necessity-driven entrepreneurship", which may be structurally more prominent in the South: women and youth attempt the entrepreneurial route, albeit with no guarantee of success, because they perceive they have no better choices. The visible result is a paradoxical reverse correlation between economic activity measures and share of women entrepreneurs, with low-income, highly rural regions like Molise and Basilicata having very high female entrepreneurship rates.

South Tyrol is a paradigmatic case of a region that is wealthy, has reached virtual full employment, ${ }^{5}$ and where gender and age inequalities in access to entrepreneurship nonetheless persist. Innovative entrepreneurship may be particularly sensitive: earlier OECD work on Missing Entrepreneurs has evidenced how women and youth are actually even less likely to launch a business in high potential sector like the digital economy, normally settling for fields with low knowledge capital areas with fewer barriers to access (cfr. "Can digital technology help level the entrepreneurship playing field?" section).

Such structural inequalities do not have a quick fix and require deep cultural changes. The Missing Entrepreneurs literature outlines priority areas for intervention such as welfare institutions, access to finance, upskilling and strengthening entrepreneurial culture. A practical first step to pursue at the local level first is to focus on subsets and intersections of these groups, whose involvement in innovative entrepreneurship is particularly desirable: young STEM graduate students, researchers and practitioners, with attention given to young women in these fields.

Young people and women of all ages suffer from a lack of starting capital, which makes the entrepreneurial choice less palatable to begin with. Moreover, the OECD evaluation of the Start-up Act highlighted how student entrepreneurship in Italy is not widespread as in other comparable countries. These are all arguments for introducing targeted schemes that offer financial security to graduate students and researchers that devote part of their time to develop an entrepreneurial project. The EXIST stipend scheme in Germany, which offers time limited monthly support to student entrepreneurs, with special provisions for those that have parenting responsibilities (BMWi, 2020b $\mathrm{b}_{[49]}$ ), may offer a useful framework. These schemes may also include mentoring and advisory services that aim at bridging more subtle, cultural-related gaps, such as lack of confidence and misconceptions about the entrepreneurial choice.

\section{Data availability: closing information gaps and promoting evaluation culture}

The Italian Start-up Act is an attractive policy to study thanks to wide availability of data about beneficiary firms and uptake of policy instruments. This is a consequence of its form - it is a registry-based initiative where beneficiaries are strictly identified - but also of explicit policy decisions taken by policy makers, who have committed themselves to making most administrative data accessible to anyone, and to setting up a monitoring and evaluation system. However, gaps in data availability persist, limiting the effectiveness and accuracy of analysis in areas that are very important for the development and effectiveness of the strategy.

A first key deficiency is employment data, which is currently available in an inadequate form. Fledgling start-ups are unlikely to generate much subordinate employment, as in early stages they might be composed exclusively by teams of entrepreneurs with one of more leaders and multiple minority shareholders. All of them may (or may not) perform work activities in the firm, on a permanent or part-time basis. There are currently no instruments to measure the size of this population, and the same applies to 
those firms that employ consultants, contractors, or gig economy workers in general. This information can be collected in two ways: surveys or amendments to company documentation. Both have been tested the latter via the introduction, in 2019, of a specific field in the startup.registroimprese.it platform - but in neither case the indication of the number of employees is mandatory.

The second gap refers to data on venture capital operations. This is a recurrent, unresolved issue in startup policy analysis, as systematic collection of detailed information on funding rounds is often impossible. Several public sector actors attempt to do so based on monitoring of specialised press and/or start-ups' and investors' own communications. This gives a partial view of the market, and accordingly estimates of its size vary widely. A particularly severe issue, especially for a policy framework that is geared towards micro-SMEs in a very early stage of development, is that this data normally does not include seed funding, which is less formalised and rarely comes from "institutional" investors.

Potentially, the Italian Start-up Act has a built-in tool to measure small size operations: data on the use of tax incentives for investments in SMEs. However, these are highly sensitive tax data that are not normally available to research, and have never been published by MISE in a detailed way - presumably for privacy issues and because this would require clearance by the tax authorities. Albeit themselves incomplete, these data could shed light on how start-ups finance themselves in their early stages, particularly when they do not access traditional credit markets, by choice or else. ${ }^{6}$

The alternative, as for employment data, is to obtain this information directly from entrepreneurs, providing for additional transparency obligations. However, collection of such data is burdensome, which advise against it being carried out in an authoritative way at centralised level. There is therefore an argument for moving this process at the local level, through ecosystem players.

There are arguments for promoting a decentralised approach to policy evaluation. As this paper series has highlighted, firms that are supported through the same national framework look remarkably different across Italy, with diverging sectorial patterns and economic outcomes. It is difficult for national legislators to observe these specificities through a single lens.

This approach could be piloted in regions where a network of public players that are in contact with registered start-ups all over their territory. If this data collection effort is successful, these may become a first breeding ground for performing analysis of labour productivity, impact of seed and later stage equity funding, and differences in growth path and innovation potential between firms that finance themselves primarily through venture capital as opposed to debt. All of these factors are crucial for an informed startup policy design, and the findings may also be relevant beyond Italy's boundaries. 


\section{Box 5.1. Policy recommendations}

Based on the empirical evidence analysed throughout this report, the government of South Tyrol could take into account the following policy recommendations aimed at strengthening its innovative start-up landscape. The actions listed both address existing weaknesses and call for better exploitation of structural strengths:

- Undertake actions targeted to improve policy transfer across the German speaking community. Identify information gaps surrounding the Italian Start-up Act, and provide as much documentation and specialised services in the two languages.

- Launch a monitoring exercise to uncover eligible start-ups that have not registered into the national policy, using Business Register data and exploiting the network of knowledge and support actors in place. Give priority to firms operating in highly innovative, high-impact sectors.

- Adopt measures to involve "missing entrepreneurs", particularly young people and women, which are sharply underrepresented among start-up founders in South Tyrol. Assess whether local government action (or lack thereof) creates adverse incentives to business creation, particularly among women.

- Introduce "soft" measures to incentivise the attraction and creation of start-ups in peripheral areas, particularly in the majority-German speaking areas further away from Bolzano-Bozen.

- Integrate the "start-up" brand and notion in local industrial policy and communication. Build upon existing ecosystem strengths, such as its high adoption rates of national incentives, and encourage reconversion into more innovative, digitised, and sustainable business models wherever possible.

- Position South Tyrol as a gateway to the Italian market for start-up entrepreneurs in the Germanspeaking world. Stress advantages of South Tyrol (e.g. tax incentives) compared to applicable legislation in surrounding culturally similar countries.

In addition to the above, the following recommendations embrace a national perspective, as they respond to issues that are common throughout Italy. These actions could be implemented locally, either directly on the initiative of the government of South Tyrol or in partnership with the central government:

- Launch a proper "scale-up strategy" alongside the Start-up Act, aiming at building a brand that is as recognised in the ecosystem as the original Act. Any scheme aimed at high-potential enterprises should put a prominent focus on the provision of patient capital.

- Encourage start-up entrepreneurship among STEM graduates and researchers. Programmes could focus on guaranteeing financial security of perspective entrepreneurs, e.g. by providing a monthly stipend, and on improving confidence and awareness about the entrepreneurial choice.

- Ideate tools to make entrepreneurial innovative projects in embryonic state emerge, and for high-skilled talents to experiment with entrepreneurial projects (e.g. innovation challenges, calls for young entrepreneurs).

- Ensure that the digital infrastructure - high-speed and high-capacity broadband, digital public administration services - is widespread and of high quality.

- Ensure wide and affordable access to high quality consulting services and testing facilities (including high-performance computing). Work with local ecosystem players to exploit effectively the European Digital Innovation Hubs scheme for the adoption of advanced digital technologies by SMEs, and encourage information sharing with equivalent bodies elsewhere in the European Union. 
- Develop "early warning" mechanisms to identify start-ups that grow fast, and whose innovations are technologically solid, market-ready, and have disruption potential.

- Improve the collection of data about employment in innovative start-ups, in order to enable accurate analysis of labour productivity, job creation and skills.

- Map significant venture capital rounds received by local start-ups, and work with the national tax authorities to improve exploitation of tax data on incentives to equity investment, which enshrine a wealth of information on seed and early-stage funding.

\section{Notes}

${ }^{1}$ For a literature review, please refer to Menon et al. 2018, pp. 52-53.

${ }^{2}$ However, the fact that several well-known scale-ups are included in this registry suggests that it could serve as a first stepping stone for a scale-up strategy. A crucial development in this respect was the extension of incentives to risk capital investments also to innovative SMEs, which became operational only in 2018 after complex negotiations with the European Commission.

3 For more information, refer to the website of the Piano Strategico Banda Ultralarga, https://bandaultralarga.italia.it.

${ }^{4}$ MISE's quarterly reports on start-ups' access to the SME Guarantee Fund shed light on the large gap in funding suffered by innovative enterprises in the South of Italy, which have lower propensity to use the instrument and normally obtain smaller, shorter-term loans.

${ }^{5}$ As of 2019 (i.e., pre-COVID-19 crisis), South Tyrol had an unemployment rate of $2.9 \%$, one of the lowest in the European Union.

${ }^{6}$ However, this should not lead to the assumption that every small-scale operation towards start-ups is facilitated by fiscal incentives, as the investor must be aware of this option and an Italian taxpayer. 


\section{References}

Aghion, P. et al. (2015), Innovation and Top Income Inequality, National Bureau of Economic

Research, Cambridge, MA, http://dx.doi.org/10.3386/w21247.

ASTAT (2019), Südtiroler Studierende an italienischen und österreichischen Universitäten 2017/18, https://astat.provinz.bz.it/de/aktuelles-publikationeninfo. asp?news action=4\&news article $\mathrm{id}=632618$ (accessed on 30 June 2020).

Biancalani, F., D. Czarnitzki and M. Riccaboni (2020), "The Italian Startup Act: A Microeconometric Program Evaluation”, SSRN Electronic Journal, http://dx.doi.org/10.2139/ssrn.3543937.

Blei, D., A. Ng and J. Edu (2003), Latent Dirichlet Allocation Michael I. Jordan.

BMWi (2020a), Customised support for new businesses affected by the coronavirus crisis, https://www.bmwi.de/Redaktion/EN/Pressemitteilungen/2020/20200401-customised-supportfor-new-businesses-affected-by-the-coronavirus-crisis.html (accessed on 29 June 2020).

BMWi (2020b), EXIST Business Start-up Grant, https://www.exist.de/EN/Programme/EXISTBusiness-Startup-Grant/content.html.

Bpifrance (2020), Coronavirus: 4 milliards d'euros pour soutenir les startups | Bpifrance servir l'avenir, https://www.bpifrance.fr/A-la-une/Actualites/Coronavirus-4-milliards-d-euros-poursoutenir-les-startups-49193.

Bria, N. (2020), Nasce CDP Venture Capital SGR-Fondo Nazionale Innovazione, https://cdp.it/resources/cms/documents/CS VENTURE 21gen20.pdf (accessed on 30 June 2020).

Calvino, F., C. Criscuolo and C. Menon (2016), "No Country for Young Firms?: Start-up Dynamics and National Policies", OECD Science, Technology and Industry Policy Papers, No. 29, OECD Publishing, Paris, https://dx.doi.org/10.1787/5jm22p40c8mw-en.

Coad, A. (2009), The Growth of Firms, Edward Elgar Publishing, http://dx.doi.org/10.4337/9781848449107.

Criscuolo, C., P. Gal and C. Menon (2014), "The Dynamics of Employment Growth: New Evidence from 18 Countries", OECD Science, Technology and Industry Policy Papers, No. 14, OECD Publishing, Paris, https://dx.doi.org/10.1787/5jz417hi6hg6-en. 
De Prato, G., D. Nepelski and G. Piroli (2015), Innovation Radar: Identifying Innovations and Innovators with High Potential in ICT FP7, CIP \& H2020 projects, http://dx.doi.org/10.2791/61591.

Dealroom (2019), 2018 full year report - Annual European Venture Capital Report, https://blog.dealroom.co/wp-content/uploads/2019/02/Dealroom-2018-vFINAL.pdf (accessed on 3 July 2020).

Del Bosco, B. et al. (2019), "Innovative startup creation: the effect of local factors and demographic characteristics of entrepreneurs", International Entrepreneurship and Management Journal, http://dx.doi.org/10.1007/s11365-019-00618-0.

Demartini, P. (2018), "Innovative Female-Led Startups. Do Women in Business Underperform?", Administrative Sciences, Vol. 8/4, p. 70, http://dx.doi.org/10.3390/admsci8040070.

European Commission (2020), An SME Strategy for a sustainable and digital Europe, https://ec.europa.eu/info/sites/info/files/communication-sme-strategy-march-2020 en.pdf (accessed on 30 June 2020).

Finaldi, R. (2018), "When Too Much Is Too Little: Evaluating the Italian Startup Act", The Journal of Private Equity, http://dx.doi.org/10.3905/jpe.2018.1.071.

Gazzetta Ufficiale (2012), Decreto Legge 179/2012, https://www.gazzettaufficiale.it/atto/serie generale/caricaDettaglioAtto/originario?atto.dataPu bblicazioneGazzetta=2012-12-18\&atto.codiceRedazionale=12A13277 (accessed on 29 June 2020).

Geroski, P. (2002), "The growth of firms in theory and in practice", CEPR Discussion Papers, https://ideas.repec.org/p/cpr/ceprdp/2092.html (accessed on 29 June 2020).

Giraudo, E., G. Giudici and L. Grilli (2019), “Entrepreneurship policy and the financing of young innovative companies: Evidence from the Italian Startup Act", Research Policy, Vol. 48/9, p. 103801, http://dx.doi.org/10.1016/j.respol.2019.05.010.

Haltiwanger, J., J. Lane and J. Spletzer (1999), "Productivity Differences Across Employers: The Roles of Employer Size, Age, and Human Capital", American Economic Review, Vol. 89/2, pp. 94-98, http://dx.doi.org/10.1257/aer.89.2.94.

Handelskammer Bozen (2017), Innovative Start-up und KMU, http://www.bz.camcom.it/de/dienstleistungen/handelsregister/dienste-deshandelsregisters/innovative-start-und-kmu (accessed on 30 June 2020).

II Sole 24 Ore (2020), Qualità della vita 2019: la classifica delle città italiane dove si vive meglio. Milano la migliore, https://lab24.ilsole24ore.com/qualita-della-vita-2019/classifichecomplete.php.

ISTAT, MISE (2018), Startup Survey 2016. La prima indagine sulle neoimprese innovative in Italia, https://www.istat.it/it/files//2018/02/Rapporto-Startup.pdf (accessed on 30 June 2020).

Klenow, P. and H. Li (2020), Innovative Growth Accounting, National Bureau of Economic Research, Cambridge, MA, http://dx.doi.org/10.3386/w27015. 
McKelvie, A. and J. Wiklund (2010), "Advancing Firm Growth Research: A Focus on Growth Mode Instead of Growth Rate", Entrepreneurship Theory and Practice, Vol. 34/2, pp. 261288, http://dx.doi.org/10.1111/j.1540-6520.2010.00375.x.

Menon, C. et al. (2018), "The evaluation of the Italian "Start-up Act"”, OECD Science, Technology and Industry Policy Papers, No. 54, OECD Publishing, Paris, https://dx.doi.org/10.1787/02ab0eb7-en.

MISE (2017), Annual report to Parliament on the implementation of legislation in support of innovative startups and SMEs, Rome, https://www.mise.gov.it/images/stories/documenti/Annual Report to Parliament Italian Start up Act 2017 - full text.pdf (accessed on 18 February 2020).

MISE (2016), Annual report to Parliament on the implementation of legislation in support of innovative startups and SMEs (2016), https://www.mise.gov.it/images/stories/documenti/italian startup act annual report to parlia ment 2016.pdf (accessed on 3 July 2020).

MISE (2020b), DL "Rilancio": gli interventi a favore delle startup e PMI innovative, https://www.mise.gov.it/images/stories/documenti/Misure DL Rilancio startup e PMI innovative.pdf.

MISE (2020a), Italia Startup Visa Report, https://www.mise.gov.it/images/stories/document/Rapporto ISV Survey ENG.PDF (accessed on 21 July 2020).

MISE (2019b), Italy's legislative framework to support innovative SMEs, https://www.mise.gov.it/images/stories/documenti/Executive\%20summary\%20innovative\%20 SMEs\%2007 2019.pdf (accessed on 29 June 2020).

MISE (2020c), Report con dati strutturali- Startup innovative 4 trimestre 2019, https://www.mise.gov.it/images/stories/documenti/4 trimestre 2019-rep-startup-stats.pdf (accessed on 30 June 2020).

MISE (2019a), The Italian Startup Act. Italy's policy framework to support innovative startups: Executive summary, https://www.mise.gov.it/images/stories/documenti/Executive\%20summary\%20ISA\%2007 20 19.pdf (accessed on 2 July 2020).

OECD (2018), OECD Regions and Cities at a Glance 2018, OECD Publishing, Paris, https://dx.doi.org/10.1787/reg cit glance-2018-en.

OECD (2016), Job Creation and Local Economic Development 2016, OECD Publishing, Paris, https://dx.doi.org/10.1787/9789264261976-en.

OECD (2011), Intellectual Assets and Innovation: The SME Dimension, OECD Studies on SMEs and Entrepreneurship, OECD Publishing, Paris, https://dx.doi.org/10.1787/9789264118263en.

OECD (2020b), Coronavirus (COVID-19): SME policy responses, http://www.oecd.org/coronavirus/policy-responses/coronavirus-covid-19-sme-policyresponses-04440101/ (accessed on 2 July 2020). 
OECD (2020c), Italian regional SME policy responses, https://www.oecd.org/cfe/leed/COVID-19Italian-regions-SME-policy-responses.pdf (accessed on 29 June 2020).

OECD (2020a), Start-ups in the time of COVID-19: Facing the challenges, seizing the opportunities, OECD Publishing, Paris, http://www.oecd.org/coronavirus/policyresponses/start-ups-in-the-time-of-covid-19-facing-the-challenges-seizing-the-opportunities87219267/ (accessed on 29 June 2020).

OECD/European Union (2019), The Missing Entrepreneurs 2019: Policies for Inclusive Entrepreneurship, OECD Publishing, Paris, https://dx.doi.org/10.1787/3ed84801-en.

Piacentini, M. (2013), "Women Entrepreneurs in the OECD: Key Evidence and Policy Challenges", OECD Social, Employment and Migration Working Papers, No. 147, OECD Publishing, Paris, https://dx.doi.org/10.1787/5k43bvtkmb8v-en.

Reuters (2020), Italian start-up 3D prints valves to help coronavirus patients, https://www.reuters.com/article/us-health-coronavirus-italy-valves/italian-start-up-3d-printsvalves-to-help-coronavirus-patients-idUSKBN2133D2 (accessed on 29 June 2020).

Scattoni, P. et al. (2019), Innovative startup localization determinants and origin: A Rome city case study, http://www.makerfairerome.eu/it/ (accessed on 29 June 2020).

Shane, S. (2009), "Why encouraging more people to become entrepreneurs is bad public policy", Small Business Economics, Vol. 33/2, pp. 141-149, http://dx.doi.org/10.1007/s11187-009$\underline{9215-5}$.

Sifted (2020), How startups are supporting Europe's coronavirus efforts, https://sifted.eu/articles/startup-initiatives-coronavirus/ (accessed on 29 June 2020).

Stuen, E., A. Mobarak and K. Maskus (2012), "Skilled Immigration and Innovation: Evidence from Enrolment Fluctuations in us Doctoral Programmes", The Economic Journal, Vol. 122/565, pp. 1143-1176, http://dx.doi.org/10.1111/j.1468-0297.2012.02543.x.

Tushman, M. and P. Anderson (1986), "Technological Discontinuities and Organizational Environments", Administrative Science Quarterly, Vol. 31/3, p. 439, http://dx.doi.org/10.2307/2392832.

UK Government (2020), Apply for the coronavirus Future Fund, https://www.gov.uk/guidance/future-fund (accessed on 29 June 2020). 


\section{Annex A. The Italian Start-up Act's policy instruments}

The following incentives and policy instruments apply to innovative start-ups from their entry in the special section of the Business Register, and for a maximum of five years from their date of incorporation.

- Dedicated digital and free-of-charge procedure for incorporation: based on a web platform, it reduces red tape and costs (savings of about EUR 2000 per incorporation) and simplifies subsequent adjustments to the deed of incorporation.

- Exemption from payment of annual fees to the Chamber of Commerce and other fees (e.g. stamp duty) otherwise due when depositing an act (e.g. annual balance sheet) at the business registry.

- Flexible corporate management: permits participants to create categories of shares with specific rights, carry out financial operations on their own shares and offer shares to the public.

- Extension of terms for covering losses: in the event of financial losses, participants receive a oneyear extension to reduce capital, as otherwise required by Italian company law.

- Exemption from regulations on dummy companies: start-ups are not subject to regulation regarding non-operational companies and businesses reporting systematic losses.

- Exemption from the duty to affix the compliance visa for compensation of VAT credit, for credit up to EUR 50000 (for other companies, the cap amounts to EUR 5 000).

- Tailor-made labour laws: start-ups are allowed to hire employees through fixed term contracts for any duration and can be renewed an indefinite number of times for 36 months. After that, the contract can be renewed once more for a maximum duration of 12 months. Standard regulations on rate of fixed-term employees over open-ended employees do not apply, i.e. start-ups can hire as many fixed-term employees as they want.

- Remuneration through stock options and work for equity schemes: participants (start-ups) can offer additional remuneration to collaborators, employees and even external service providers through stock options and work equity schemes. These participative financial instruments do not concur to determine the taxable labour income, i.e. people who get a stock option do not pay taxes on this type of income.

- Tax incentives to corporate and private investors who invest in start-ups: for individuals a deduction of income amounting to $30 \%$ of the amount invested, with maximum limit on the size of the deductible of one million euros. Legal entities receive fiscal deduction on taxable income equal to $30 \%$, with maximum limit of EUR 1.8 million.

- Possibility to raise and collect capital through equity crowdfunding platforms. Italy was the first country worldwide to introduce ad hoc regulations on equity crowdfunding in 2013 followed by France and Germany in 2014, USA and UK in 2015.

- Fast-track simplified and free access for innovative start-ups to SME Guarantee Fund: this State Fund enables access to credit through guarantees on bank loans (in the measure of $80 \%$ of the total loan). The amount covered by the public guarantee is up to EUR 2.5 million. Unlike other companies, start-ups can obtain the guarantee without costs. Fast-track refers to the fact that their files are given priority over those concerning other companies. Unlike other companies, the SME 
Guarantee Fund does not evaluate any balance sheet or business plan submitted by the concerned start-up, i.e. the guarantee is provided automatically, based on the "merit of credit" evaluation carried out by the lending bank.

- Service and support for start-ups looking to access foreign markets from the Italian Trade Agency: start-ups receive a $30 \%$ discount on standard fees applied to services such as targeted advice on legal, business and/or fiscal activities. Free-of-charge participation of selected start-ups in international events is also provided.

- Italia Start-up Visa programme: fast-track, web-based procedure for obtaining self-employment visas to Italy. It is addressed to non-EU citizens who intend to establish an innovative start-up in Italy. In addition, non-EU citizens who already reside in Italy, e.g. for study, and intend to prolong their stay in Italy with the purpose of establishing an innovative start-up, are allowed to convert their residence permit to a self-employment type through a similar fast-track, web-based procedure (“Italia Start-up Hub" programme).

- Fast fail bankruptcy procedure: participants are exempt from normal bankruptcy processes, preliminary closure agreements, and forced liquidation if the start-up becomes over-indebted. 